\title{
RELATE-AND-DISCOVERY: \\ EXPLORING THE CONFLUENCE OF UX DESIGN AND \\ ELECTRONIC WORD-OF-MOUTH IN TRAVEL TECHNOLOGY
}

by

Peter Albert Weir

Bachelor of Commerce in Marketing, Concordia University, Montreal, Canada, 2015

\begin{abstract}
A Major Research Paper presented to Ryerson University in partial fulfillment of the requirements for the degree of

Master of Digital Media
\end{abstract}

In the Program of Digital Media

Toronto, Ontario, Canada, 2017

(C) Peter Albert Weir, 2017 


\section{AUTHOR'S DECLARATION FOR ELECTRONIC SUBMISSION OF A MRP}

I hereby declare that I am the sole author of this MRP. This is a true copy of the MRP, including any required final revisions.

I authorize Ryerson University to lend this MRP to other institutions or individuals for the purpose of scholarly research.

I further authorize Ryerson University to reproduce this MRP by photocopying or by other means, in total or in part, at the request of other institutions or individuals for the purpose of scholarly research.

I understand that my MRP may be made electronically available to the public. 


\author{
RELATE-AND-DISCOVERY \\ Master of Digital Media, 2017 \\ Peter Albert Weir \\ Master of Digital Media, Ryerson University
}

\begin{abstract}
Due its costly and intangible nature, travel-related purchases involve a lot of complex decision-making, and are therefore deemed high-risk. However, since the turn of the millennium, as web-enabled technologies grew increasingly more prevalent, the manner in which people seek information has evolved, thus distorting our traditional understanding of the buyer's journey. Using search-powered, online platforms, consumers now deploy an arsenal of means to discover new goods, services, and activities.
\end{abstract}

While there are countless price comparison websites and virtual communities for obtaining travel information, all of the existing networks neglect the most effective and longstanding breed of communications-a form that regularly outperforms the standard approaches to advertising: word-of-mouth (WOM). Namely, a process in which consumers can discover information not only through search, but by relating to one another. As a result, the market is devoid of a tool for sharing personalized, experience-based, destination-specific travel recommendations with friends and family.

Through Dispatch, a mobile app prototype and research proxy, the efficacy of online WOM (eWOM) will be explored further, revealing how this behaviour phenomenon coexists with the intricacies and nuances of user experience (UX) design. 


\section{ACKNOWLEDGEMENTS}

This author would like to thank his supervisors, Dr. Jeremy Shtern and Dr. Louis-

Etienne Dubois, for their insight, guidance, and lucid commentary through the duration of this work.

The author also thanks Ryerson faculty members and program luminaries, Dr. William "Michael" Carter and Dr. Alex Ferworn, for their leadership all throughout the year, and for being available, understanding, and compassionate in an especially dire time. Further, special acknowledgments to Dr. Gregory Levey, for his candor and invaluable advice right out of the station, which put this train on the right track.

I would like to express gratitude for my fellow students in the MDM 4.0 cohort, whose hard work, dedication, and unshakeable talent provided me with a well of inspiration from which I drew. Likewise, I wish to thank my friends, in Toronto, Montreal, Victoria, and Vancouver, for pushing me throughout this process, despite the constant badgering and playful ridicule.

My completion of this program would not have been possible without the Yeates School of Graduate Studies, including Gino Guercio, and for that, I will remain forever grateful.

Finally, I must thank my family for all the love, enthusiasm, and unwavering support they have provided me through the years. 


\section{Table of Contents}

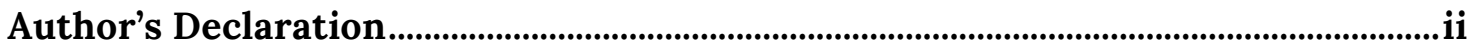

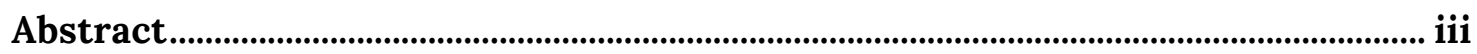

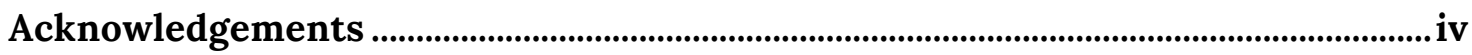

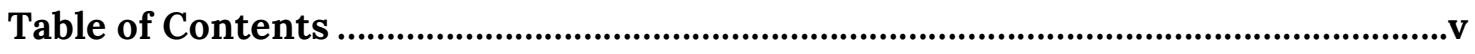

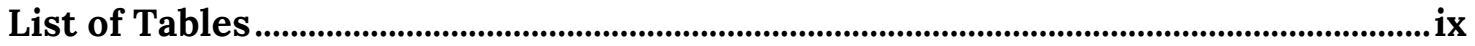

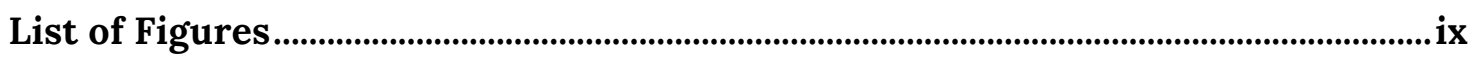

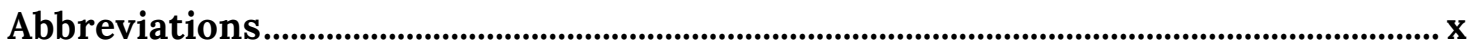

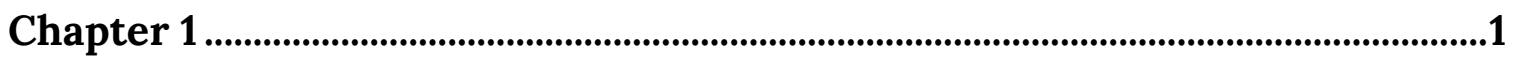

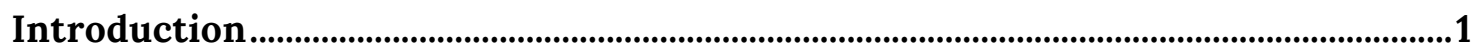

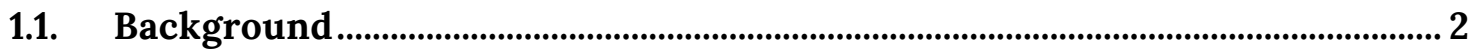

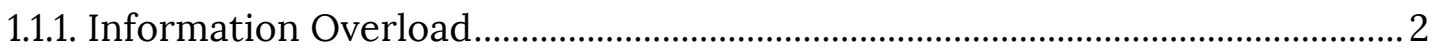

1.1.2. Consumer Purchase Journey ............................................................................. 3

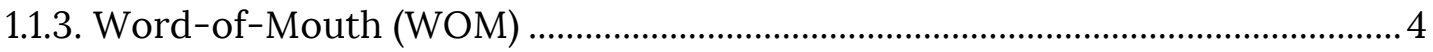

1.1.4. Electronic Word-of-Mouth, Reinterpreted .................................................... 6

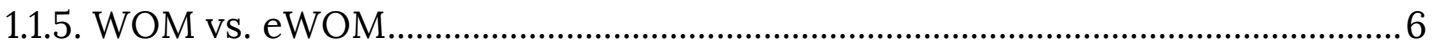

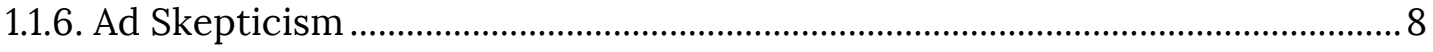

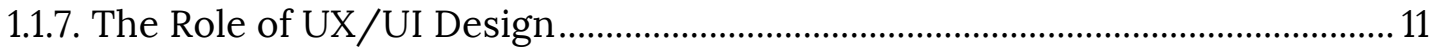

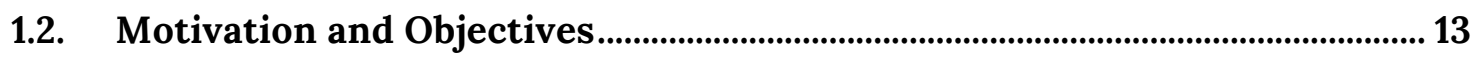

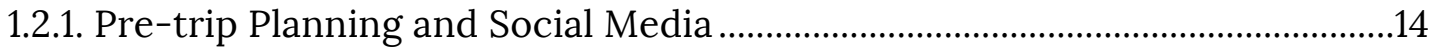

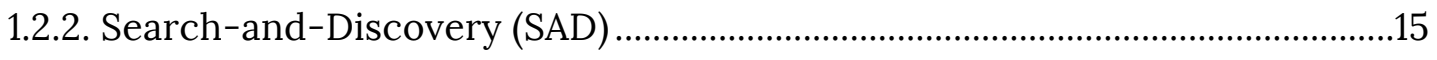

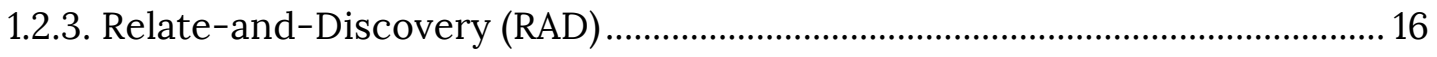




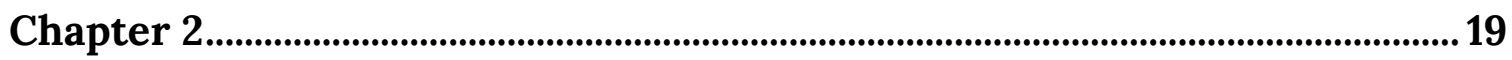

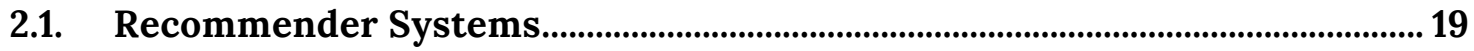

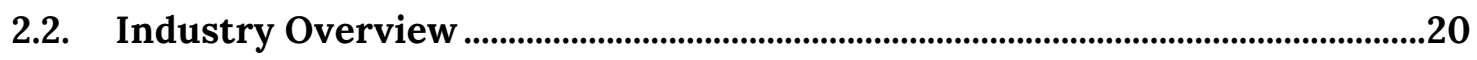

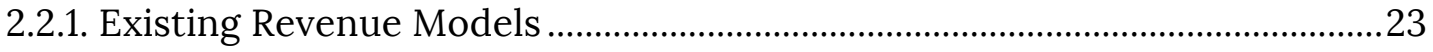

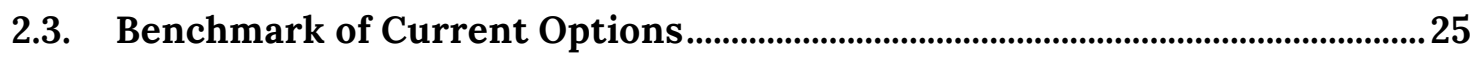

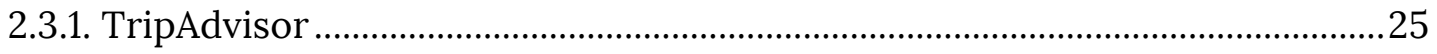

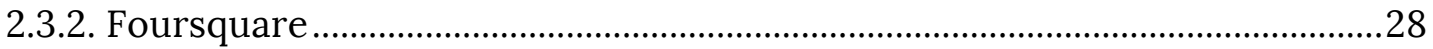

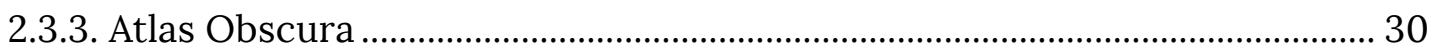

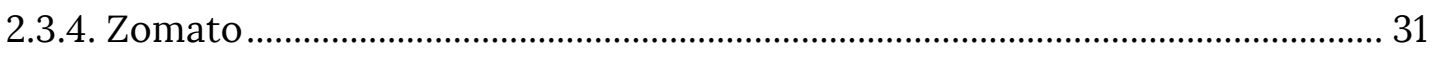

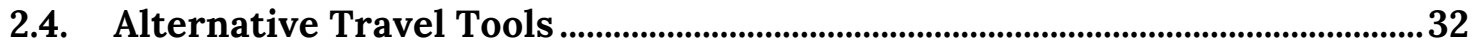

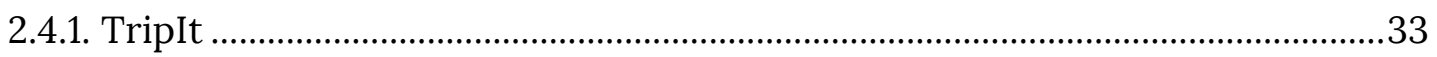

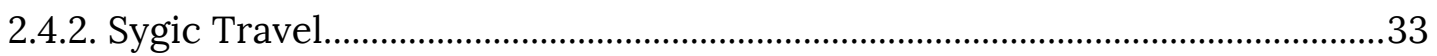

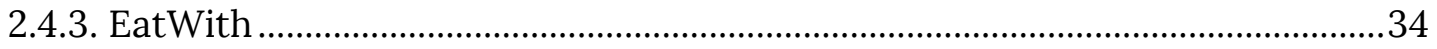

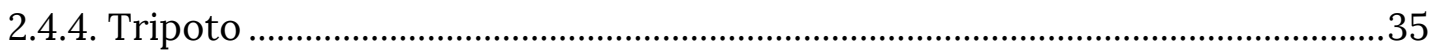

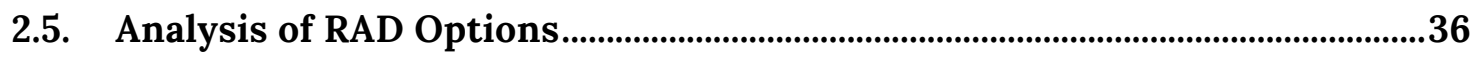

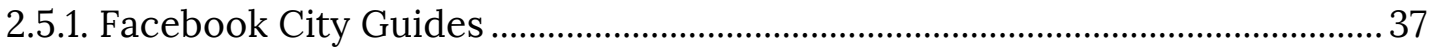

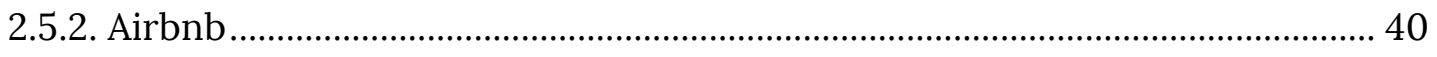

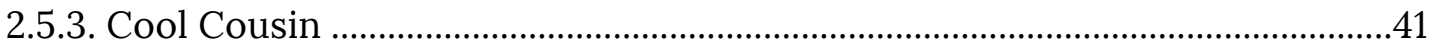

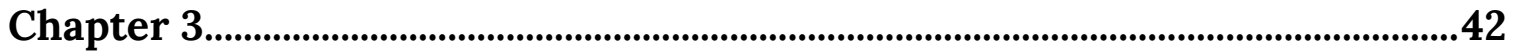

3.1. Mobile Application Proposal................................................................................................ 42

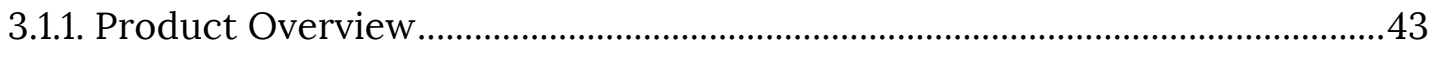

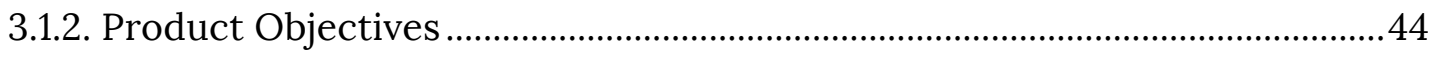


3.2. UX/UI Design Philosophy ……………………..................................................... 45

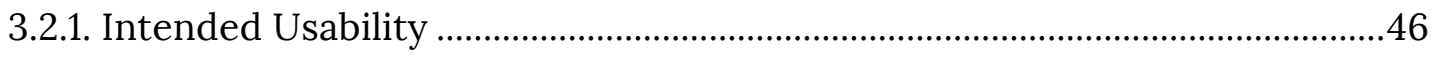

3.2.2. Private Network........................................................................................... 4 4

3.3. Core Functionalities.............................................................................................48

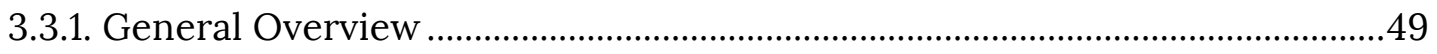

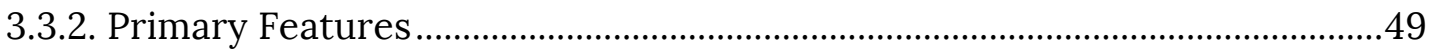

3.4. Peripheral Functions ………………………………......................................................53

3.4.1. Offline Capabilities ...............................................................................................53

3.4.2. Proximal Notifications ..........................................................................................54

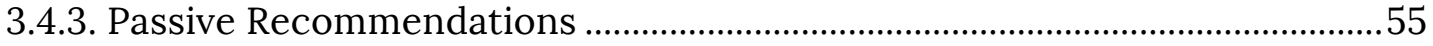

3.5. Business Model ............................................................................................. 55

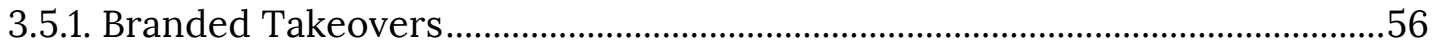

3.5.2. Native Advertising........................................................................................... 57

3.5.3. Partnerships and Specialized Vouchers...........................................................58

3.5.4. Premium Usage (.............................................................................................59

3.5.5. Data Analytics /Customized Reports ................................................................. 60

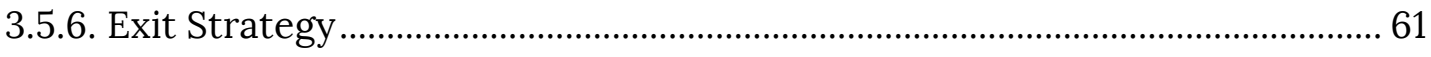

3.6. User Acquisition Plan .................................................................................................... 61

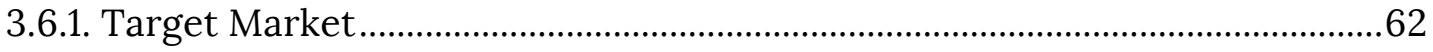

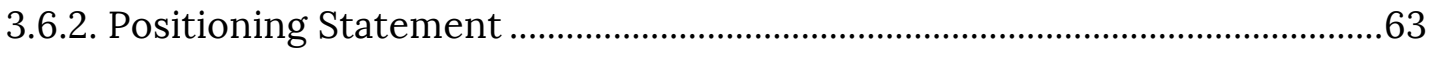

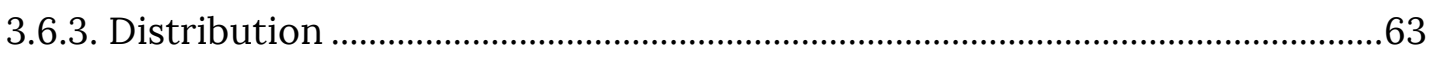

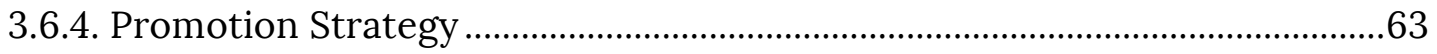

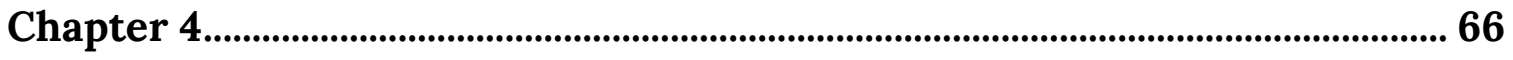

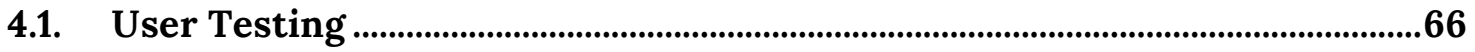




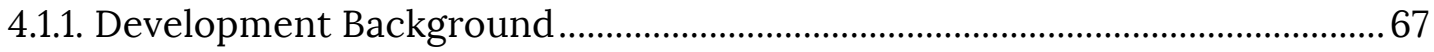

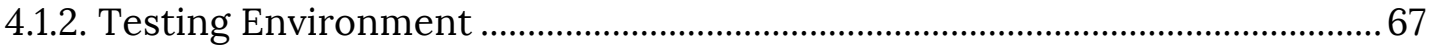

Chapter 5............................................................................................................................... 69

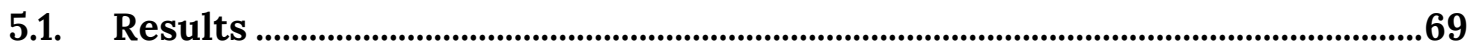

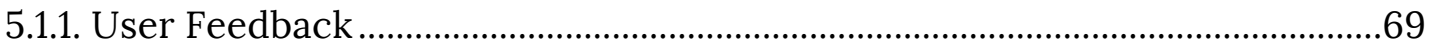

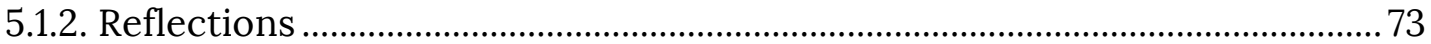

Chapter 6 .........................................................................................................................

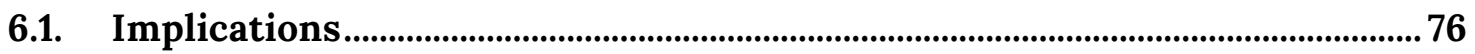

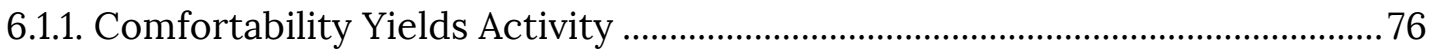

6.1.2. The Enduring Power of Normative Influence …................................................. 77

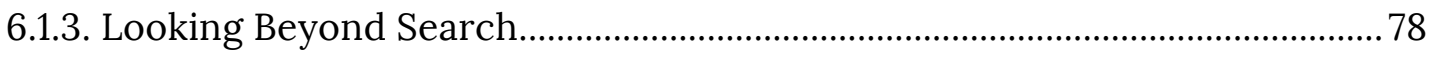

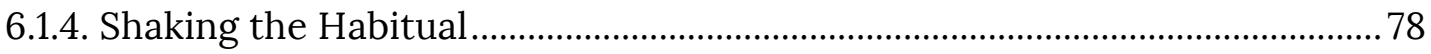

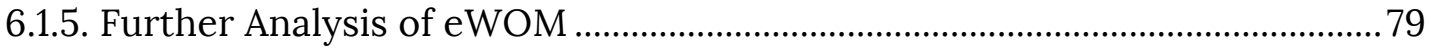

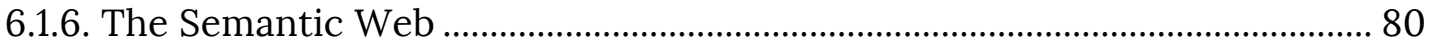

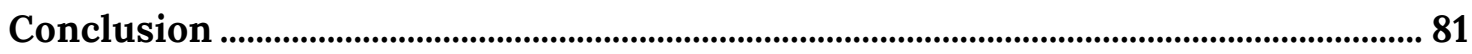

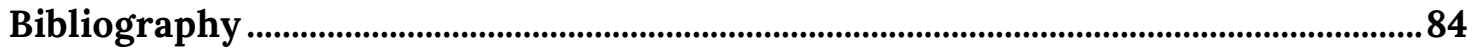




\section{List of Tables}

Table 4.1: Participant Demographics ...............................................................................................68

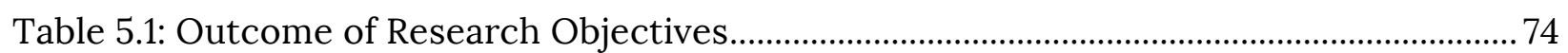

\section{List of Figures}

Figure 3.1: Value Proposition Canvas.......................................................................................... 47

Figure 3.2: User Flow Diagram ...........................................................................................5 


\section{Abbreviations}

$\begin{array}{ll}\text { eWOM } & \text { Electronic Word-of-Mouth } \\ \text { OURS } & \text { Online User Review Sites } \\ \text { RAD } & \text { Relate-and-Discovery } \\ \text { SAD } & \text { Search-and-Discovery } \\ \text { UGC } & \text { User-Generated Content } \\ \text { UI } & \text { User Interface } \\ \text { UX } & \text { User Experience } \\ \text { WOM } & \text { Word-of-Mouth }\end{array}$




\section{Chapter 1}

\section{Introduction}

Since the turn of the millennium, the digital landscape has been replete with innovation, affording consumers with a surplus of tools, resources, and methodologies for obtaining information. The proliferation of web-based technologies and new media has dramatically reshaped how we learn, grow, and behave, thus distorting our traditional understanding of what drives people to make decisions (Edelman \& Singer, 2015). Once a routine activity, the notion of patronizing an establishment at random-and with little to no thought-is now a behavioural relic from times past; these days, consumers place considerable reliance on Internet-enabled devices to aid both their social and economic intelligence (Bigne et al., 2015). Similarly, the manner in which people seek information has evolved: Consumers will deploy an arsenal of means to discover new goods, services, and activities, and in no industry is this more true than travel and tourism (Hernández-Méndez et al., 2015). In the domain of travel-which, for academic purposes, is often referred to as holidaymaking-the journey from idea conception through evaluation to actual purchase is significantly more complicated than accustomed marketplaces. What with airfare, accommodation, food, and countless other activities, the sheer volume and array of expenditures will force any consumer to carefully ruminate on how, when, and where they part with their hard-earned cash (Hernández-Méndez et al., 2015). As it happens, the search for information has become tantamount to the planning stage of a trip (Pabel \& Prideaux, 2016). 


\subsection{Background}

The early 2000s saw the beginnings of what became Web 2.0, where online technologies espoused characteristics that are more familiar by today's standards. This includes user account creation, interface design, file storage, peer-to-peer networking, and social bookmarking (O'Reilly, 2005). It was under these conditions that a number of major players emerged, offering a richer user experience, the ability to generate content, and mass participation-all of which becoming staples of the modern virtual travel community (Buhalis \& Law, 2008). In due course, destination marketing was born, and travel suppliers started working tirelessly to disseminate favourable and enticing materials, while establishing customer-facing management systems to combat negative feedback.

Suddenly, Internet users were churning out content, communicating with one another, and sharing their points of view (Buhalis \& Law, 2008). Moreover, because of the web's inherent searchability, all of this peer-driven information could be retrieved by anyone with the time and willingness to do so, as it was now a matter of public record.

\subsubsection{Information Overload}

To presume that consumers are benefitting from greater access to informationfacilitated by the Internet-would be unwise and shortsighted, as it gives rise to infobesity; a recently-coined, colloquial term used to describe information overload (Puryear et al., 2013). Broadly speaking, there is difficulty associated with making decisions, effectively, when one is endowed with too much information, as consumers are left befuddled and irresolute (Chen et al., 2003). Even before the Internet, an overabundance of information was seen as counterproductive to the decision-making process; the dilution effect, for instance, posits that excess information can lead to a judgment bias, where the consumer's 
resolve is undermined by irrelevant or neutral information (Aronson, 1972). In consideration of the digital economy, though, infobesity is having a profound effect on the consumer purchase journey. The seemingly bottomless depths of the World Wide Web are aplenty with data, intelligence, and peer-focused knowledge, which can be summoned effortlessly, and, not to mention, instantaneously. The power differential has shifted from the hands of businesses to those of the people, ergo shattering conventional approaches to marketing goods and services. And considering the intricacies and nuances of holidaymaking, the tourism sector has been particularly marred by the interconnected nature of the World Wide Web (Hernández-Méndez et al., 2015).

\subsubsection{Consumer Purchase Journey}

Regarding consumer behaviour, in historical teachings and academic literature, the purchase journey is delineated as a five-stage model, with "evaluation of alternatives" or "consideration" aptly positioned in the middle (Kardes, 2002). Yet, the axiom supporting this school of thought completely ignores the realities of infobesity, which has beset the contemporary marketplace-travel included (Murphy et al., 2007). The preponderance of consumer review platforms, deal hunting, and price comparison tools have, in virtually every respect, destabilized the conventions and practices of tourist-driven organizations (Hernández-Méndez et al., 2015). The search for information is now a cornerstone of the buyer's journey, as consumers leverage the knowledge to reduce uncertainty; information provides people with the requisite assurance to move forward with their decision, but it does not necessarily mean that they are making the best choice possible (Bigne et al., 2015). Accordingly, the immediacy of such information has facilitated a give-and-take relationship shared between public constituents, where they serve not for remuneration, but the power 
of speech, and the ability to impart wisdom. It should be noted, however, that in lieu of voicing for the sake of being heard, more often than not, consumers tend to complain: The impetus to express one's attitudes, judgments and beliefs-regarding products and services-is far stronger when the experience was negative (Cheung et al., 2009). Businesses are now at the subjugation of the people, where any semblance of malpractice or wrongdoing can jeopardize a firm's operations, and the continuity thereof. Altruism aside, at the end of the day, consumers are merely striving toward a more cohesive society, to prevent other people from enduring the same misfortunes, while holding businesses accountable and promoting higher standards of conduct. Thanks to the Internet and our wherewithal to connect with one another, with respect to the digital economy, it is the vox populi who shall ultimately triumph (Bonezzi et al., 2016). Interestingly enough, the underlying philosophy driving this new breed of consumer behaviour also happens to represent the most potent, longstanding, and tried-and-true manifestation of advertising and communication; a format that regularly outperforms the traditional approaches to creating demand: word-of-mouth (WOM).

\subsubsection{Word-of-Mouth (WOM)}

In point of fact, WOM is the very first incarnation of the advertising medium, having germinated long before anyone was familiar with the activity, much less the term used to describe it. To trace the origins of WOM would be something of an impossible task; since the genesis of communication and language, humans have been relaying advice, tips, and general counsel, and usually for the betterment of their peers (Duffy, 2015). Owing to the complexities and logistical challenges of travel, consumers have developed a strong interdependency on one another, to inform their respective experiences; as Duffy (2015) 
points out, once upon a time, travellers would affix handwritten notes to the trees of Africa, instructing their fellow comrades of what is to come. Nowadays, though, most consumers are well-acquainted with the notions of WOM, and the inordinate capacity of one's voice when expressed with the utmost force and lucidity. Research has shown that a 7 percent bump in positive WOM for a company can increase its revenues by a staggering 1 percent (Samson, 2006). The airline industry is particularly susceptible to the ramifications of WOM, and even more so when the information is negative. One study found that over a 20-month period, 1,000 complaints will cost airlines an accumulated loss of USD \$8.1 million (Luo, 2008). For organizations that serve the travel and tourism sector, what was once an afterthought is now a matter of constant surveillance: WOM is a powerful, enduring, and contagious event, which, in most cases, cannot be controlled (Bonezzi et al., 2016). It can, however, be facilitated.

In 2015, market research powerhouse Nielsen administered its biannual "Global Trust in Advertising" report, where some 50,000 respondents were surveyed online. The results, while not surprising, lend further credence to the actualities of marketing in the twenty-first-century: 83 percent of consumers completely trust recommendations from friends and family, where 83 percent are liable to act on said recommendations (Nielsen, 2015). The efficacy of WOM is irrefutable, particularly in comparison to other prevalent forms of advertising. With respect to Nielsen's 2015 survey, runner-up to WOM-in terms of advertising effectiveness-is consumer opinion discovered online, via forums, review sites, chat rooms, or otherwise, which clocked in at 65 percent. What's more, the degree to which consumers trust advertisements through other notable avenues, such as branded websites, television commercials, promoted search engine results, and social media ads, which registered at 70,63, 47, and 46 percent, respectively (Nielsen, 2015). That is to say, 
when it comes to trust and subsequent action, WOM is the most influential and powerful form of advertising communications. Even through online mediums, WOM is an inexorable force, but our current understanding of this behavioural phenomenon is flawed, calling for a reinterpretation of these communicative events.

\subsubsection{Electronic Word-of-Mouth, Reinterpreted}

For reasons unknown, to date, the lion's share of past research has explored WOM vis-à-vis electronic word-of-mouth (eWOM) as separate, almost mutually-exclusive occurrences. Operating under this context, WOM is thought to occur solely between two individuals, in-person; a one-to-one informational transaction. eWOM, on the other hand, is considered an anonymous exchange among one-to-many people(s), through online channels, and thus with significantly less credibility (Duffy, 2015; Cheung et al., 2009). Why, exactly, is beyond the scope of this report. Nevertheless, understanding the perception of WOM and eWOM in existing literature presents a decidedly critical research gap, as previous studies have failed to consider the online exchange of information among friends and relatives; namely, people who share a pre-existing relationship. Assessing the potency of eWOM amid the confines of anonymity is unnecessary, as it assumes that close-knit individuals refrain from transmitting ideas, advice, and general guidance through electronic-based mediums. In sum, eWOM and related behaviours do not occur exclusively between anonymous sources.

\subsubsection{WOM vs. eWOM}

WOM is thought to succeed the traditional eWOM because it is inherently trustworthy and reduces time (Duffy, 2015). Be that as it may, due to the personal, physical 
nature of WOM, at any given moment, the average consumer simply cannot relate with anyone they so desire. For instance, a close friend who resides across town, in a neighbouring country, or on another continent. Therefore, the newfound interpretation of eWOM is not only on par with WOM, but perhaps more authoritative and compelling, because technology allows it to occur at anytime and anywhere.

However ubiquitous, though, the above-mentioned construal of eWOM is often thrown into question, largely due to the plight of credibility (Cheung et al., 2009). Given the impersonal natural of consumer review sites and other, one-to-many eWOM networks, it is the responsibility of the end user to ascertain some level of trust when gauging the caliber of a message. In Cheung et al.'s (2009) study of eWOM, historically, evaluating a message is contingent on the reliability of its sources (information providers), as well as the quality of its argument-or, more precisely, its informational factors. This, of course, is a behavioural philosophy rooted in the dual-process theory, which is generally concerned with, "How different types of influences affect the persuasiveness of online consumer reviews" (Cheung et al., 2009, p. 13). Nonetheless, seeing that eWOM platforms are fuelled by online recommendations provided by total strangers, Cheung et al. (2009) dispute the sufficiency and importance of using such parameters to assess credibility. What, exactly, drives an individual to login to a forum and share their perspective with the masses? The consumer's motive is profoundly unclear, casting a shadow on the integrity and veracity of the message that is ultimately provided (Cheung et al., 2009). By concentrating on not the motives of the information provider, but the heuristics of the receiver, the researchers sought to better understand how normative influence can shape the consumer decision-making process, and whether it could eventually affect the overall sales of a product or service. Further, to expand on existing research revolving around eWOM credibility, Cheung et al. 
(2009) unpack a handful of other renditions of the dual-process theory, including Yale's model, which posits message, source, and audience as three, key factors that govern people's opinions. However, as noted above, Yale's variation is still deemed inadequate, particularly in light of the Internet's increasing relevance. Thus, Cheung et al. (2009) build upon the theory by appending more determinants to the model: argument strength, recommendation framing, recommendation sidedness, source credibility and confirmation with receiver's prior belief. Recommendation framing is thought to have a profound impact on the consumer's outlook, resulting from the confidence of the presenter when the information is conveyed (informational influence). Surely, authority and knowledge are powerful determinants in the domain of eWOM, as it offers a level of clout and certitude that is difficult to asperse, directly. Moreover, because of our traditional understanding of eWOM-and its one-to-many, largely anonymous nature-on top of authority and knowledge, past research has failed to examine the informational influence of online recommendations when the receiver well-acquainted with the provider. In regard to WOM, indeed, we are unequivocally aware of how pre-existing, social relationships can offer a degree of credibility that is parallel to none. Yet, through online channels, there is little known about the efficacy of a message when it comes from a close friend or family member.

\subsubsection{Ad Skepticism}

Due to the increasing relevance of virtual communities, online review platforms, and social media, consumers now have access to a diverse array of sources to seek and gather information, which led to the genesis of eWOM. Particularly in recent years, advertisers have lost a significant amount of power, and thus can no longer rely on traditional methods 
and practices for disseminating messages and creating demand. As a result, marketers have to be more creative than ever when devising promotional material-in lieu of speaking to the consumer directly, informing them of their latest offering, advertisers must proceed with an air of tactfulness. In most cases, any outward attempt to market a good or service will be met with irritation by the consumer, and, accordingly, skepticism (Chari et al., 2016).

In the wake of this paradigm shift, a new genre of marketing has taken shape: native advertising. That is, the strategic infusion of a promotional message with a piece of genuine, value-adding, and natural content. If a consumer has no reason to believe that a particular article, video, or podcast actually came at the behest of a brand, then they will consume the media willingly (Chari, S. et al., 2016). To this point, native advertising is of considerable interest to both brands and researchers, as its efficacy in today's climate is widely known, and quite strong. Consequently, to combat any potential apprehension on the side of consumers, brands have formulated an entirely new and alternative method for producing advertising material: user-generated content (UGC). Perhaps another harbinger of the consumer's growing influence, UGC is now tremendously popular among companies that maintain a strong presence online (Chari, S. et al., 2016). If executed well, the emergence of UGC allows brands to sit back, relax, and observe the people as they assume the responsibility of creating and distributing the message. However, in similar fashion to the traditional concept of eWOM, the value and credibility of UGC remains a problem for advertisers, as consumers grow ever more cognizant of these practices.

Interestingly, Chari, S. et al.'s (2016) report on consumer trust in brand recommendations found that of all things, ad skepticism fuels the integrity of a message. The manner in which Internet users discern trust in online environments varies from platform to platform. However, through mainstream channels where consumers are likely 
to share user-generated brand content (e.g. Facebook), it is understood that perceived credibility is contingent on the sharer's integrity, ability, and benevolence (Chari et al., 2016). In regard to Facebook, trust is directly correlated to the user's perception of whoever has posted the content, and whether they perceive the action as being helpful and altruistic (Chari, S. et al., 2016). For the average Facebook user, there is no reason to believe that another person is sharing content to explicitly promote a brand. Further, the remaining elements of how individuals perceive user-generated brand recommendations comprises the integrity and ability of the sharer. Although, the process by which an Internet user draws a conclusion is highly subjective, and impossible to predict (Chari. et al., 2016). In whatever way, no matter how it is viewed upon, consumers will always trust the actions, behaviours, and sentiments of their friends and family (Nielsen, 2015). As noted above, the bedrock of trust in an online environment is the perceived benevolence in the individual sharing the information. Why, exactly, are they enlightening their friends to this specific piece of content? In populated, sweeping networks such as Facebook, it is difficult to fully understand. That is, when the information is published in the most public of settings: the News Feed. At any rate, when the informational transaction occurs between two friends or family members who enjoy a close, genuine relationship, there is virtually nothing to doubt about the intent of the message. Obviously, the user is making this information available to their friends and relatives for the benefit of the individual. The presence of a strong bond, coupled with a close psychological proximity, imbues the recommendation with an extraordinarily high degree of credibility, which is unreachable through other forms of messaging. If the status remains quo and these trends persist into the time ahead, the only viable format in which advertisers can enact marketing programs will be through WOM and eWOM. While not the most apocalyptic of hypothetical 
scenarios, still and all, such a future would serve to the benefit of consumers, cementing the new power differential, and forcing businesses to concentrate on their core competencies: providing value-adding goods and services.

\subsubsection{The Role of UX/UI Design}

How, when, and where an Internet user is exposed to a piece of content is a major determinant of how said content is perceived-if that is an advertisement or something created by another, regular consumer (Creusen et al., 2005). In online environments, much of the context is informed by the design; namely, the look-and-feel of the interface, the aesthetics, colour scheme, and tone, as well as the navigational flow between all of the sections. User interface (UI) design is largely focused on the visual elements of a digital product, whereas user experience (UX) is concerned with the overall endeavour, including customer satisfaction, utility, and digestibility of the information (Kujala et al., 2011). As Cheung et al. (2009) discovered, a product's design can, indeed, influence how users respond to and interact with eWOM content, be it through different features, functionalities, or the general performance of the platform. Further, should an online tool reach a point of maturity, any major amendments to its usability may upset the most active and loyal users, causing them to abandon the network in favour of somewhere else (Kujala et al., 2011). Still, at practically all stages of an application's lifetime, both UX and UI design play an instrumental role in the extent to which consumers use the product: In order to build an active community of users, app makers and designers must strike a balance easeof-use and serviceability, which are the two most critical prerequisites for any burgeoning digital product (Creusen et al., 2005: Davis, 1989). 
Within the past decade, mobile applications, in particular, have emerged as an overwhelmingly popular vehicle for entrepreneurs who opt to pursue a new media venture, creating a market that is plagued by fragmentation (Datta et al., 2012). On the whole, it has never been easier for an individual to found a business around a mobile app product. The technological renaissance has brought forth tremendous opportunity, where anyone with the requisite ambition can, given the right set of circumstances, attain some degree of success, however they choose to measure it. Should the founding individual possess the right skills, in some cases, the start-up costs of building an app are practically nonexistent (Blank, 2013).

Howbeit, aside from an application's ease-of-use and usefulness, there is another aspect of UX design-of equal importance-that will dictate the breadth and longevity of a product: its financial viability and capacity to generate revenue. Regardless of whatever problem or pain point an application is vying to resolve, ultimately, the makers will have to leverage the platform's appeal and create a reliable, consistent, and scalable revenue stream. Further complicating the matter, when devising and implementing a monetization strategy-a task that is already challenging in its own right-one must also contemplate how such a drastic move will impact the application's overarching UX, as perceived by the user. Supposing the revenue model comes at the expense of the product's value and functionality, it is fair to assume that said user would feel compelled to abstain from further use of the app. Behind the screens, this is precisely the dilemma that has bewildered software developers since the dawn of the Internet; an eternal predicament, which, for all intents and purposes, is analogous to the age-old debate, most commonly denoted as art versus commerce. 


\subsection{Motivation and Objectives}

Against this background, which introduced infobesity and ad skepticism, and how both elements are transforming the consumer purchase journey, along with the preponderance of online user review sites (OURS), eWOM, UGC, and UX design, all that remains is to evaluate its accumulated effect on the travel industry. Or rather, the tools, resources, and methodologies that are currently being employed by holidaymakers to elevate their travel experiences, and what destination marketers and tourism organizations are doing to stay competitive in this evolving media climate. It is no longer sufficient to develop technologies for Web 2.0, as our relationship with digital media has transcended its defining characteristics. That said, what the next wave of innovation will entail is not immediately clear, thus it is critical for travel suppliers to maintain a sense of agility when navigating the coming years (Morrow, 2014).

All things considered, there is one aspect of human behaviour that has not been adequately served. Above-stated, the merits of WOM and eWOM are some of the only constants in a sea of variables-a form of communication that rises above infobesity and ad skepticism, regardless of the context. Relatedly, another practice that has endured the test of time is UX/UI design, as it must be executed in consonance with the customs of the people, and their behaviour toward technology.

At present, however, the market is devoid of a tool for sharing personal travel recommendations with friends, family, and general acquaintances. Consumers will typically relay their ideas, advice, and suggestions through a diverse range of channels-namely inperson, through email, and social media-leaving the recipient with a disorganized mess of information. Moreover, due to the preponderance of native applications and mobile-based 
media, numerous studies have explored technology's profound impact on travel-related decisions, proving the consumer's appetite for newly updated, location-specific, peersponsored information (Hu et al., 2015). OURS have managed to attract and retain a substantial base of individuals who regularly employ their services to exchange travel tips. Further, beyond user traffic, the value of a consumer-oriented review network is largely derived from its capacity to promote WOM, which transcends any other form of advertising (Nielsen, 2015). That being said, the above-mentioned review platforms are not designed, explicitly, to facilitate what Nielsen (2015) has dubbed the strongest manifestation of WOM: personal recommendations.

\subsubsection{Pre-trip Planning and Social Media}

For travellers, no activity is more critical than the pre-trip planning stage. On top of the commodities of travel, including airfare, transportation, and accommodation, consumers also spend a considerable amount of time searching for places of interest (Pabel \& Prideaux, 2016). Aforementioned, the preeminence of new media technologies has utterly transformed this process; information is more accessible, and, in turn, consumers are more informed, thus increasing their bargaining power. It does not matter what the traveller is looking for-just about every piece of information one might be searching for is merely a few clicks away (Pabel \& Prideaux, 2016). However, there is a new method in which Internet users have employed to obtain travel-related information: social media. Indeed, this newfound resource is far more common with younger audiences, but it is important to understand why consumers are drawn to these platforms. Firstly, there is an element of sociability, which is unmatched in terms of immediacy and reciprocity. However, social networks can also offer a profound degree of entertainment, which makes the 
information-and its consumption-all the more palatable (Pabel \& Prideaux, 2016). When a consumer discovers something on social media, it is presented in a novel compelling way, and is thus much more likely to resonate; put simply, the content is equal parts engaging and informative. Granted, how an Internet user digests the information is conditional on the environment in which the message is being delivered. On platforms where participants are required to use their real, given names, the ideas they ultimate share are typically more representative of their own beliefs. Conversely, when there's no method for verifying the identity of the users and participants can adopt pseudonyms, the threat of bias looms rather large (Pabel \& Prideaux, 2016). No matter what, though, in the presence of pseudonyms and anonymity, consumer should take the information with a grain of salt; as Hensel and Deis (2010) allude to, it is remarkably easy for businesses to exploit these platforms by peddling fake reviews and ratings, in an effort to increase saleability.

\subsubsection{Search-and-Discovery (SAD)}

Notwithstanding the popularity and fortitude of TripAdvisor, Foursquare, Atlas Obscura, and Zomato, all of the above-mentioned OURS promote a specific kind of behaviour that has driven our relationship with web-enabled technologies since the genesis of the Internet. Among other things, the common thread linking these networks is their technical classification, search-and-discovery (SAD): How a user experiences the platform and extracts value is married to the function, process and enactment of searching. Needless to say, search is a hallmark of the Internet; it regulates, it governs, it is at the helm of virtually everything we do online. In the brief but fabled history of the World Wide Web, at the forefront, Google has occupied the role of our shepherd, which is best evidenced by the search titan's de facto byname, "The Gateway to the Internet." 
The public's relationship with the Internet is closely tied to search, and in many instances, this inborn tendency is our best method of identifying and uncovering what we want. Yet, as we evolve with technology, every day, people are devising and discovering alternative means for accomplishing their goals. Infobesity has weakened consumer confidence, and thus existing platforms, tools and resources that exclusively offer SAD services will likely drift closer to the wayside. The underlying characteristics of innovation call for the advancement of technological capabilities that better accommodate the people, and are, in general, more human-centric. This is not to herald the demise of SAD and search engine providers, but rather, to build awareness around the idea that there are other options, choices and possibilities at our disposal; if not today then perhaps tomorrow.

\subsubsection{Relate-and-Discovery (RAD)}

In view of WOM's effectiveness and the revised interpretation of eWOM-that it does, indeed, occur between two familiar parties-while the favourability of SAD diminishes, a new and unprecedented breed of information discovery will emerge in its wake. By design, it will neglect the havoc and disorienting nature of infobesity, thereby presenting consumers with a novel approach to unearthing valuable, dependable, and actionable information: relate-and-discovery (RAD). In lieu of taking to an online search engine, through the virtues of interconnectivity, people will consult those who know them best-their peers. With the current state of affairs, the process of poring through large swathes of data to even find just a modicum of value is far too cumbersome and anachronistic. The web was originally envisioned as common, egalitarian network that serves for the betterment of humanity (Hodgson, 2016). This sentiment, however 
credulous, still rings true today among industry leaders and digital luminaries, including the Internet's founding father himself, Sir Tim Berners-Lee. By all accounts, the web operates akin to an oligopoly, where a dozen or so entities control and oversee the overwhelming majority of user traffic. Thus, in the event that a consumer is already within the ecosystem of a dominating entity, their fundamental freedoms to act and do as they please are severely limited (Hodgson, 2016). In response, numerous Internet theorists have pointed to a future that is significantly less concentrated, where services like social networking and communication are driven by the people (i.e. users) and their communities. In other words, a decentralized, level playing field that champions the human spirit and how we connect, learn, and discover together (Hodgson, 2016). Even with its roots in idealism, the fundamental principles of what is known as Web 3.0-or the Semantic Webspeak to the latent capacity of eWOM, and, accordingly, eWOM-nurturing platforms; honest, sincere, and human-to-human informational transactions that are infused with substance because it comes from the heart.

Formulated in response to infobesity and the challenges consumers face when using the Internet to find dependable, trustworthy information, relate-and-discovery is defined as such: The act of discovering information within a social context, either in-person or through virtual means; product, service, or activity recommendations shared among friends/relatives. Thus, an online tool that promotes RAD can be interpreted as: Specialized Internet applications that enable two-way communication between friends and relatives, for the sole purpose of exchanging personalized recommendations on any given topic. 


\subsubsection{Relating vs. Searching}

When SAD platforms were introduced in the mid-2000s, the travel industry shouldered much of the economic, social, and technological ramifications, and scrambled to devise and implement an adequate solution (Hu et al., 2015). Peer-to-peer information networks have annexed the traditional purchase-decision model, affording the consumer with more authority and influence than ever before. However, the existing tools have failed to recognize the most tried-and-true manifestation of WOM, depriving its users from connecting with people they already know and whose opinions they trust. Search is just one method in which consumers can exercise to obtain information, but, as we evolve with technology, many are growing wary of the process, finding it burdensome; with respect to Duffy's (2015) analysis of WOM and consumer review sites, 26.7 percent of surveyors mentioned that refining the search terms to produce better, more informative results took far too much time. One respondent (63, male, USA) was quoted as saying, "You'd have to wade through a huge amount of information, which is a big downside when you're planning a holiday" (Duffy, 2015, p. 138). The study, of course, was primarily concerned with consumer decision-making in regard to choice of hotel accommodation. Nonetheless, one could argue that a discovery of this sort may indicate a behavioural shift; the basis for taking time with a search, fine-tuning the parameters to satisfy the user's preferences is to establish a degree of perceived similarity-or homophily-between the user's interests and the technology. That said, homophily is defined as a mutually-held set of interests-among people-and is thus a categorically human event. In order to attain a favourable outcome (i.e. sound recommendations), one must set aside the time and energy to provide an algorithm with sufficient data. However, to circumvent the search function altogether, and 
instead, discover information by way of connecting with friends and family, is, in one way or another, to cut out the middleman.

\section{Chapter 2}

\subsection{Recommender Systems}

Recommender systems have subsumed the role of the traditional travel agent. The web service could handle the booking of key purchases, like airfare and hospitality, publish tourist-centric editorial, or facilitate activity discovery; in the current media climate, online travel tools are almost expected to produce automated recommendations, personalized to the end user (Buhalis \& Law, 2008). Many of today's foremost travel websites are decidedly sophisticated in this regard, providing recommendations that are not based entirely on what users have indicated they prefer, but their browsing habits and purchase history, too (Hamari et al., 2017). In view of these technological advancements, mobile and web applications have invested a lot into personalization, and their capacity to serve bespoke recommendations. Indeed, accommodating the needs, wants, and preferences of the end user is a natural progression from the static, bulletin board-like content delivery of Web 2.0. The technology that is facilitating this newfound thirst for individualization is presumably getting stronger with every passing day, as data accumulates, and the machinery grows ever more intelligent (Hamari et al., 2017). Some organizations and new media ventures will pursue this route, opting for better science to ameliorate their core offering. At the present time, however, virtually all travel applications are entrenched in search, where performance is tied to a recommender system. While 
there are SAD tools abound, particularly for travel, the principles of RAD have yet to fully materialize in an online environment. Some web platforms are symptomatic of RAD, albeit unwittingly, and without emphasis on its defining qualities. Therefore, to better understand the capacity of RAD and how it can manifest, one must conduct a benchmark of the current offering, which is largely composed of SAD tools, virtual communities, and social networks.

\subsection{Industry Overview}

Before reviewing several of the top online travel platforms, it is necessary to evaluate the digital travel market, from the perspective of consumers, as well as the state of its businesses, both conventional and forward-leaning. Due to the costliness and intangible nature of travel, the tourism sector is markedly complex, which is why such products and services are categorized as high-risk (Hernández-Méndez. et al., 2015). Whether it is a casual weekend getaway or a year-long journey abroad, holidaymaking is an immensely popular, undying activity that attracts more than a billion people every year (CREST, 2016). As a whole, the industry is not only booming, but ballooning: Outbound travel sales are said to have increased by 8 percent from 2015, topping the USD \$2 trillion mark in 2016, and still growing (ITB Berlin, 2016). With respect to the digital travel market, numerous reports have indicated sharp growth in the coming years, as worldwide travel sales are expected to surpass USD \$817 billion by the year 2020 (eMarketer, 2016). Despite a growing number of Millennials who are partaking in holidaymaking, regarding travel patterns, this demographic is fairly homogeneous with older, more experienced consumers from the Baby Boomer era (ITB Berlin, 2016). However, there is one, stark difference between the 
two groups: Millennial travellers possess a voracious appetite for technology, relying on web-enabled devices to conceive, plan, and execute trip activities.

Accordingly, the proliferation of consumer-grade information and communication technologies-geared toward tourists-have heralded the demise of the traditional travel agency: an institution that was once believed to be invaluable (Hernández-Méndez et al., 2015). In a report from Current Issues in Tourism, Hernández-Méndez et al. (2015) sought to examine the influence of what they branded "Travel 2.0" applications, and how it affects tourism behaviour. That is, to verify which sources of information are the most influential to consumers when deciding on a travel destination. Interestingly, the report aimed to distinguish between the conventional understanding of WOM, in relation to the opinions and recommendations shared online by sole individuals who are predisposed to content creation. That is, consumers who run a blog or contribute articles to other digital publications. Still and all, Hernández-Méndez et al.'s approach to making sense of the twenty-first-century traveller neglected the revised interpretation of eWOM, operating under the assumption that friends and family members do not exchange travel guidance through digital means. Concerning the study, an objective of critical importance-as detailed by Hernández-Méndez et al.-was to establish the "socio-demographic and navigation characteristics" that account for the various online media and related tools tourists use for trip planning, and the extent to which said tourists share their experiences on blogs and social networks (Hernández-Méndez et al., 2015, p. 1002). Should the study conclude a growing appetite for promulgating first-hand accounts of travel, particularly within a social networking environment, it would perhaps improve the prospects of a mobile application that is expressly designed to facilitate such behaviour. Moreover, owing much to the fact that tourism is a largely experiential industry, the valence of WOM has 
become an all-important strategy employed by consumers to mitigate risk. Appropriately, Hernández-Méndez et al. postulate two of the most influential factors that shape the travel decision-making process, which comprise perceived risk and search for information. This is precisely where the Internet shines; a predominance of consumers deploy web-enabled technologies to inform their travel-related decisions, citing ease-of-use, ability to save time, and control-apropos of the planning process-as the primary reasons for doing so (Hernández-Méndez et al., 2015).

Indeed, there is an acute sense of empowerment that underscores the abovementioned point, which regards control; in lieu of visiting a travel agency where a liaison handles all of the pressing tasks, consumers enjoy assuming those responsibilities and forging their own paths (i.e. reclaiming their own sense of agency). Moreover, prior to reviewing Hernández-Méndez et al.'s findings on WOM, it is important to denote how the behavioural phenomenon is categorized with respect to alternative sources of information. In tourism, a piece of information is thought to originate from either one of two places: commercial and noncommercial. Further, one must also consider the context in which a message is delivered: personal or impersonal. Unsurprisingly, both WOM and the traditional eWOM are deemed noncommercial, personal transactions. Time and time again, WOM, in particular, has been found to be a tremendously influential source of information, namely because it allows prospective holidaymakers to conceptualize the destination long before the purchase is finalized. In regard to electronic-based mediums, HernándezMéndez et al. found that eWOM is invariably more credible than other sources of information-barring the one-to-one, traditional WOM-because those who generate content and share their opinions online have no vested interest in the companies, brands, or products they are discussing. While the study's portrayal of eWOM is still flawed, the 
research emphasizes how such transmissions of information will evolve in the coming years, especially amid the promise of Web 3.0 technologies. To that point, HernándezMéndez et al. (2015) expound the many ways in which the orthodox web is outworn, dubbing it excessive in nature, and far too intelligent for the common individual. Web 3.0, on the other hand, is all about a more open, honest and sincere community that thrives on the energy of its stakeholders (i.e. participants). In addition to words, Web 3.0 is said to integrate other variations of communicative means, including spatial information, sounds, and imagery, thereby evoking natural, human feelings. In plain English, this idea is alluding to the proliferation of richer, bolder, and more dynamic media-something that Hernández-Méndez et al. (2015) predict will dramatically alter future instances eWOM, especially in regard to travel. As the researchers put it, "Information, space, and technology will be integrated to enrich both the description of the traveller's experience and improve the accuracy of the information sought by the prospective traveller" (Hernández-Méndez et al., 2015, p. 1007).

\subsubsection{Existing Revenue Models}

Concerning the digital travel market, there are a handful of well-established business models that are proven, time-tested, and thus validated by the market. Upon review of existing online tools that cater to travel and tourism, in addition to more traditional, largely offline properties (such as travel guides), there are two different models that have prevailed: one of which, anchored from the perspective of conventional business, and the other, design. This age-old debacle has long put app makers at odds with one another; how much of the business do you sacrifice for design, and vice versa? Furthermore, with respect to the many different tools and resources at the disposal of 
holidaymakers-be it applications, OURS, or travel guides-by and large, businesses will typically employ either one of two monetization policies: upfront cost or free-to-use. The former relies on an initial sum, provided by the customer, which grants immediate access to the product's materials. In contrast, the latter approach permits usage at no cost, to attract customers from the onset, and encourage purchases down the road. Charging customers upfront is typically associated with more conventional tourist-driven organizations, like paperback travel guides or sightseeing services. In this way, such a monetization policy is primarily focused on revenue, stemming from the time-honoured practices of business-to-consumer marketing (Kardes, 2002). On the other hand, free-touse-which is also known as freemium-is more closely related to web-based products, like mobile applications and travel forums, where in lieu of direct remuneration from the customers, oftentimes, it is the advertisers that foot the bill. In the absence of sponsored content, freemium products may offer additional services, features, or benefits that can be procured by the users-provided they are willing. In the eyes of the consumer, stumbling on a promotional gambit every now and again is a fair price to pay for unlimited and free use. That is, if said promotional gambit is seamlessly integrated into the UX without disrupting the app's core functionality, much less the usability.

To date, however, there is no evidence of a firm employing a healthy mix of the two philosophies. Alternatively stated, a travel product or service that embraces the tenets of design, while relinquishing some creative liberties to facilitate monetization. Nowadays, more than ever, understanding how both of these credos work in conjunction is imperative to building a value-adding product or service; something that people will actually want to use, thereby establishing an audience that marketers can leverage to dispatch advertisements. 


\subsection{Benchmark of Current Options}

Across the new media landscape, there are multitudes of social networking applications and web platforms that specifically cater to the demands of tourism. Of the existing tools, those most pertinent to the discussion comprise the aforementioned TripAdvisor, Foursquare, Atlas Obscura, and Zomato.

\subsubsection{TripAdvisor}

TripAdvisor, for instance, is the most established online portal for consumer-driven, travel-related reviews. Now lauded as an early adopter of UGC, TripAdvisor is considered the world's largest travel site, boasting 350 million unique visitors every month ${ }^{1}$. That being said, however, TripAdvisor's scope is extremely broad-in addition to consumer reviews and travel editorial, TripAdvisor has expanded its offering over the years, including a tool for booking vacation rentals, hotel rooms, flights and more. Additionally, TripAdvisor is first and foremost a desktop website, primarily employed as a community forum for people to obtain information, thus lacking the requisite characteristics of a social networking service. Regarding the site's influence, many studies have explored its impact on the travel industry, as well as the consumer's resolve. Most relevant to the objectives detailed earlier, in 2015, Andrew Duffy assessed the comparative influence of travel review platforms and friends and family members. In other words, the traditional understanding of eWOM versus WOM. Again, we see these peer-to-peer informational transactions being analyzed separately. However, Duffy's take on WOM is a little more compromising; by concentrating on the

\footnotetext{
${ }^{1}$ Figure was obtained through TripAdvisor's official website, which can be retrieved at https://www.tripadvisor.ca/PressCenter-c4-Fact_Sheet.html.
} 
arena of hotels and hospitality, Duffy learned that WOM and eWOM are not mutually exclusive, but rather, two occurrences that operate in tandem: one informs the other, and vice versa. Despite eWOM's growing influence in the travel industry among other, pertinent markets, Duffy asserts that it will never replace WOM, but instead, serve as an accoutrement. Through a comprehensive survey, Duffy strived to better understand how recommendations can affect the choices consumers make when deciding on accommodation. That is, should a holidaymaker receive a recommendation through both TripAdvisor and a close friend or relative, which piece of information will have a greater effect on their choice of hotel?

Duffy (2015) was able to further assess the power of a recommendation when received through TripAdvisor, in addition to a close friend or relative. Through a survey, the following question was posed: "Do travellers trust TripAdvisor as much as friends and guidebooks?" (Duffy, 2015, p. 131). Despite the broad nature of the question, the results speak to the underlying strength of WOM and related behaviours. The vast majority of respondents answered "no," thus leading the study to conclude that TripAdvisor is, without doubt, significantly less credible than a recommendation from a close friend or family member: 63 percent of surveyors declared that friends are more trustworthy than any other sources (Duffy, 2015). One surveyor, in particular, remarked: "[WOM and OURS] have to work together, and a friend's recommendation would be much more valued to me, and sometimes that's how I do it also. I ask a friend and then I check against TripAdvisor" (Duffy, 2015, p. 134). In order of significance, friends and relatives were considered the most credible, followed by TripAdvisor, and physical guidebooks at a distant third. Interestingly, of those who took to online consumer review sites, 42.3 percent said they compared the recommendation against TripAdvisor, to corroborate the information. Further, Duffy also 
presented another, notable idea that is thought to play a big role in the efficacy of eWOM. That is, the perceived similarities in terms of personal taste and interests that are shared between the recommendation provider, and the receiver-a psychological appellation that was previously alluded to called homophily. First and foremost, homophily is widely regarded to be the mainspring of human relations, as it establishes and breeds a mutual connection on the basis of values, beliefs, and preferences. In the presence of strong homophily, the process of forming relationships and making conversation is demonstrably easier, thereby cementing a bond between the two individuals (McPherson et al., 2001). In whatever way, time and time again, friends were found to be the most trusted source, because, quite simply, they understand the traveller's needs and interests. Case in point, when probed on the matter, one Canadian surveyor replied with, "My friend could say that they have an amazing wakeboarding thing, they have a bar on the water, they know me, while TripAdvisor and Lonely Planet don't know me" (Duffy, 2015, p. 135). This dynamic, while obvious, illustrates the key, distinguishing factor, which is paramount to RAD: friends and family members will always be as forthright as possible, sparing no detail, even if it is discouraging-a profoundly human notion that is simply absent from consumer review sites like TripAdvisor, let alone paperback guides (Duffy, 2015). For instance, in the East Village neighbourhood of downtown Manhattan, there is a popular Indian restaurant called Milon. In addition to serving high-quality, authentic Indian cuisine, patrons are drawn to the restaurant due to its unique ambiance. Among other things, the walls are adorned with a myriad of polychromatic lights, creating a playful, exciting, and celebratory dining atmosphere. However, on the back of Milon's success, three additional Indian restaurants opened up in the adjacent business quarters, all of which decorated in the exact same manner and style. Now, on the block sits four identical Indian restaurants, each a carbon 
copy of Milon, where the differences are imperceptible, especially to the average, less informed traveller. That said, should someone provide counsel to a friend, they would instruct said friend to politely ignore the rest-including the countless restaurant personnel, situated atop the steps, cajoling potential customers-and head for the entrance on the top left of the stairwell. Admittedly, any holidaymaker, in theory, could learn of this while researching New York City online. However, when an individual is disseminating personalized recommendations to their close friends and family, one can surmise that such a critical piece of information would never be overlooked.

\subsubsection{Foursquare}

Nevertheless, any budding new media application that services the travel industry is sure to be weighed against other, pre-existing resources. While nowhere close to TripAdvisor's level of popularity, Foursquare is another major player in domain of travel technology. Billed as a recommender system, Foursquare is a mobile app and social network where users can 'check-in' to various establishments-bars, small businesses, restaurants-and observe the most loyal patrons through an informational leaderboard. Despite waning in popularity over the past few years, Foursquare still enjoys a monthly active user base of over 50 million people (Novet \& Weber, 2015). It should be noted however, that Foursquare's core functionality is geared toward local inhabitants of a particular area (i.e. well-acquainted denizens), thus rendering its services futile in the eyes of a foreign traveller. Moreover, Foursquare's deliberately crafted marketing regime intimates a tool for identifying activities and places worth seeing. However, in actuality, the application's main draw is the leaderboard and mayorship component, engendering a weirdly competitive user environment where people compete to patronize the same 
establishment over and over again. This methodology—however peculiar—is Foursquare's motivational instrument; their unique brand of incentive to promote repeat usage. Today, however, Foursquare is not nearly the behemoth it once was; over the years, the application has suffered from a dwindling user base, forcing upper management to reconsider its chief value proposition (Novet \& Weber, 2015). Originally, Foursquare's UX was designed around the act of searching. Thus, users bore the sole responsibility of conceiving an idea, formulating a query, and perusing the list of results, manually, with the hopes of discovering something of value. Although, after many years of accumulating data, insights and customer feedback, Foursquare's usability is no longer contingent on search: Regarding places of interest in the immediate area, users now receive personalized suggests-courtesy of Foursquare-that are entirely based on the individual's browsing history, past purchases, and check-in records. Indeed, such an approach to content delivery might draw the ire of today's most impassioned privacy advocates, but if Foursquare's shift portends anything, it is that information discovery is moving away from the act of searching, and more toward the prescription of ideas. That said, when dealing in recommendations and tailored content, there is a decidedly thin and often blurred line separating usefulness and intrusiveness. In Hamari et al.'s (2017) study of personalized product recommendations, the efficacy of a message was analyzed against its context and framing, as perceived by the reader. In the report, Hamari et al. identified two ways in which a message is phrased (based on the data provided): firstly, the passive form, where recommendations refrain from addressing the user, explicitly, in favour of using words like "others have" or "picks of the day." Conversely, when composed in the active form, messages are formulated directly to the user, opting for pronouns such as "we" or "you" to deliver the recommendation (Hamari et al., 2017). To recapitulate Hamari et al.'s findings, 
unsurprisingly, advertisements that were conveyed in the passive form vastly outperformed that in the active form, yielding a significantly higher click-through rate. However, and most enlightening, the study found that any kind of personalized product or service recommendation-irrespective of context-that is purely derived from past browsing and purchase data is generally seen as intrusive, off-putting and, in extreme cases, aggravating (Hamari et al., 2017). To this point, merchants that currently extend personalized product recommendations should proceed with caution; there is a fair degree of sensitivity that engulfs such information, no matter how the message is framed-that is, unless it is provided by another, familiar person who is perhaps well-acquainted with the receiver.

\subsubsection{Atlas Obscura}

Even with its journalistic resolve and niche appeal, Atlas Obscura is yet another online platform that serves the travel and tourism industry. Founded in 2009, Atlas Obscura began as an online magazine and news outlet for all things travel, exploration, history and science. Compared to TripAdvisor, as well as paperback stalwarts Lonely Planet, Atlas Obscura strives to champion activities and foreign destinations that are novel, strange, and lesser known. As a travel publication, since its launch, Atlas Obscura has cultivated a loyal following of holidaymakers turned thrill-seekers who consider themselves on the cutting edge of modern day exploration. Nowadays, in pursuance of strong editorial, Atlas Obscura relies on its impassioned community of travel-savvy users to conceive, produce and submit recommendations, thus crowdsourcing all information that is ultimately published on the site. For all practical purposes, Atlas Obscura is best described as an amalgamation of TripAdvisor and Foursquare; it is an all-in-one platform 
for discovering activities in a particular city or region, wherein activity suggestions are provided by people, curated by the site's editors, and ranked according to popularity with a picture and caption denoting each item. Aesthetically, Atlas Obscura is emboldened by a salient, consistent and reliable design schema, which quickly becomes familiar after repeated use. Moreover, there is, in fact, a social networking component to it-Atlas Obscura encourages account registration, and, just like Foursquare, usability revolves around 'checking-in' to various places and logging activities. The information is presented through a grid-like feed that resembles a leaderboard, thus offering a mild degree of gamification; users can compete with one another, to not only visit or patronize as many places as possible, but to make edits and contributions to the network's vast body of materials.

\subsubsection{Zomato}

Primarily employed as a website, along with a mobile app equivalent, Zomato is the foremost SAD platform for restaurants, cafes, and other food-related establishments. At present, Zomato is available in 23 countries around the world, with over a million restaurants listed, and receives approximately 90 million visitors a month ${ }^{2}$. By all accounts, Zomato has accomplished a great deal since its launch in 2006, but the context in which people use the website is markedly ambiguous. To date, Zomato has yet to publicize when, specifically, consumers are using the platform to discover restaurants. Are the bulk of their users local residents, or visitors? Who is more inclined to use their services? Based on observational research, oftentimes, people will visit the site as a last-ditch effort, perhaps

\footnotetext{
${ }^{2}$ Figures were sourced from the Zomato website, which can be retrieved at: https://www.zomato.com/business/advertise
} 
due to time sensitivity or otherwise. Nevertheless, Zomato has found tremendous success in building a dynamic and searchable registry of the world's myriad of restaurants, whereby consumers can rate, review, and supplement the content. Whether users take to the platform while abroad or not, Zomato is an exceptionally simple resource that has furthered the merits of eWOM. The network's orderliness and navigational efficiency serves as a touchstone for future applications that promote location-specific information; cities are not presented as a whole, but rather, by the neighbourhoods and districts that make it up. The locality of the information is amplified to a remarkable degree, which substantiates a consumer demand for hyper-specificity, in addition to well-designed, wellorganized, and itemized recommendations (Hu et al., 2015; Delgado, 2017).

\subsection{Alternative Travel Tools}

For all the popular, more omnipresent websites and mobile tools for aiding the travel experience, there are multitudes of other, albeit homogeneous options available to the consumer. In view of the mobile travel app marketplace, products are generally grouped under one of the following categories: trip and itinerary planning, as well as travel guides. Many have cultivated a substantial community of users, especially the platforms that promote some degree of sociability. Howbeit, the vast majority of applications that compete in this arena are designed to solve one, overarching problem, which often plagues the notion of travel: logistics. Or rather, the detailed coordination of a trip, including the people involved, facilities, supplies, and, most critically, transportation. While these applications are varied in terms of serviceability, and, from an impartial standpoint, could be deemed valuable, they all share a fundamental purpose: to reduce the severity and 
likelihood of a travel-induced headache, particularly when journeying from one place to another.

\subsubsection{Triplt}

Perhaps the most reputable and trusted of them all, TripIt is advertised as a tool for creating travel itineraries and trip planning. On TripIt's website, the company's vision is promulgated as such, "To enable the perfect trip, and bring delight to travellers." Some of its features include the creation and management of master itineraries, which can be access through a mobile device and shared with other people. Moreover, TripIt users are also permitted to sync their calendars with the app, create a traveller profile, and, interestingly, auto-import previously-drafted plans. Upon further review, however, while TripIt is touted as a consumer-facing product, to all appearances, its services are primarily targeted at other businesses. In addition to TripIt Pro, which retails at USD $\$ 49.00$ a year, TripIt offers Teams, an enterprise package that is priced as high as $\$ 159.00$ for an annual subscription ${ }^{3}$. What, exactly, TripIt Pro and TripIt Teams provides that the standard, freeto-use version lacks is not immediately obvious. Nonetheless, their continued operations and ostensible success could be interpreted as a demand for greater organization in the domain of travel.

\subsubsection{Sygic Travel}

Unlike TripIt, Sygic Travel is an online trip planning tool that is explicitly geared toward consumers. Formerly known as Tripomatic, Sygic is predominantly focused on

\footnotetext{
${ }^{3}$ Pricing figures were gathered from the official TripIt website, which can be retrieved at: https://www.tripit.com/
} 
handling logistical tasks and challenges that holidaymakers face when booking a trip abroad. Though, in lieu of providing a slew of beneficial features, Sygic Travel is entirely centered around its interactive map plotter, where users can visualize the entire trajectory of their travels. Once a trip has been mapped out, Sygic will then provide its users with product and service recommendations, whether for accommodation, nourishment, as well as air and ground transportation. Presumably, Sygic works in partnership with sundry businesses that are emphasized across the site. Thus, for all practical purposes, like many online booking tools, Sygic operates more as an affiliate than a consumer-minded platform. That said, the mechanics of Sygic Travel's product-the interactive mapping tool-is exceptionally well-designed, which makes the normally rigorous task of planning a trip a rather entertaining, compelling, and imaginative experience. Without a public record of Sygic's traffic and user base figures, though, it is hard to determine the level of popularity that the site currently enjoys. According to corporate communications and marketing material, Sygic is allegedly trusted by millions of travellers around the globe. Comparatively, Sygic's keystone offering is not only superior to the competition, but objectively useful.

\subsubsection{EatWith}

Regarding travel, there are few activities more anticipated than dining, as food is imperative to the cultural experience. In light of this sentiment, EatWith was founded to provide travellers with an uncomplicated tool for identifying and booking reservations in foreign destinations. Operating as a SAD service, EatWith maintains a database of thousands of menus in over 200 countries worldwide, which are curated by a team of 650- 
plus hosts ${ }^{4}$. Once a user has decided upon a restaurant, they can book a reservation through EatWith, and look forward to an authentic dining experience led by a knowledgeable local. Of course, such a web-based service is sure to draw comparisons to restaurant SAD colossus Zomato. However, EatWith is distinguished by its matchmaking service, which connects travellers with local inhabitants who are well-acquainted with the area, and the cuisine therein. In any event, EatWith is a SAD service that relies on the merits of search to drive its business. Even so, after the user has settled on a restaurant, once on vacation, they will, in fact, discover more through the virtues of relation. EatWith is thus a manifestation of both $\mathrm{SAD}$ and $\mathrm{RAD}$, proving that while consumers are accustomed to the act of searching, lurking within is an innate desire to connect with other human beings.

\subsubsection{Tripoto}

Lastly, and perhaps most germane to the principles of RAD, is Tripoto; another online platform that services holidaymaking. Modelled after TripAdvisor, Tripoto is a community-driven network of travellers who employ the forum to swap experiencedbased insight, tips, and general guidance. At the heart of Tripoto's functionality is the trip publishing tool, where users can document a trip and publish the itinerary for all to see. Thus, content creation occurs after the fact-once the individual has returned from their travels-whereas consumption of site materials takes place before. Generally, users tend to put together diligent itineraries that document the various activities they experienced while in the area. The duration of each trip-published by the user-is clearly denoted, for

\footnotetext{
${ }^{4}$ Figures were obtained from EatWith's official website, which can be retrieved at: https://www.eatwith.com/brand/about/
} 
the logistical benefit of prospective travellers who are currently in the planning stage of their trip. Itineraries typically have the air of a list-based article, designed to entice clicks through a compelling headline. For instance, under the 'trending' section of Tripoto's homepage, the following trip has amassed over 400,000 views, "7 Stunning Infinity Pools in

India Worth Visiting In your Lifetime." Assuming that Tripoto refrains from inflating its user traffic, the popularity of the above-mentioned article gives substance to the consumer's enthusiasm for eWOM. However insightful, though, the identities of those publishing content on Tripoto are, in all likelihood, unknown to the end user. Thus, despite nurturing a strong and passionate community of ardent holidaymakers, users are never going to fully trust the information found on the platform.

Once again, all of the aforementioned travel planning tools have neglected the latent capacity of eWOM. To date, there are no examples of a travel-oriented, yet social application that is expressly designed to connect individuals with those who they already know. A place where people can feel comfortable sharing experience-based guidance with their friends and family members.

\subsection{Analysis of RAD Options}

In regard to the current social networking landscape, there are dozens of mobile and web-based platforms that cater to the principles of RAD, albeit indirectly. What's more, many of these players are dominating forces in today's technological climate, and should be addressed accordingly. 


\subsubsection{Facebook City Guides}

Of those embracing the tenets of RAD, most worth noting is social media behemoth Facebook, which, at the beginning of 2017, introduced a new service, aptly dubbed City Guides. Facebook's new feature enables its users to select a city or region of the world, and petition their network-connected friends for advice. To all appearances, Facebook has executed the foundational elements of RAD, as it promotes the exchange of recommendations between friends-a behavioural tendency paramount to the RAD doctrine. That said, the innate characteristics that shape the RAD user experience is contingent on psychological proximity among users, and the intimacy thereof. Facebook, like its contemporaries, is an all-encompassing, across the board social media network that has cast a wide net in terms of scope. Users can connect with other people, instant message, chat, create and market events, and upload photographs, all of which are components that comprise Facebook's social networking activities. Additionally, Facebook has invested huge sums in other areas of business, including artificial intelligence, where the technology company hopes to beat out major players such as Microsoft, Google, and IBM, Apple, and Amazon ${ }^{5}$.

Despite Facebook's recent foray into the domain of RAD-and its capacity to facilitate such informational transactions-the very thing that makes it successful may also be its undoing: there are far too many active users currently on the platform. The sheer volume of any given person's noted 'friends' on Facebook has no basis in reality. And, when an individual takes to the platform to solicit recommendations, assessing the value of the

\footnotetext{
5 While not pertinent to the discussion, this information was obtained from Wired, which can be retrieved at: https://www.wired.com/2016/11/google-facebook-microsoft-remaking-around-ai/
} 
information is often difficult. Processing the information, too, is a tricky feat, namely due to the variance of ideas, which might contrast or complement the individual's personal taste and preferences. Further, despite Facebook introducing City Guides, there's no guarantee that its vast base of users will actually employ the feature. Generally speaking, not everyone who uses the social media platform is inclined to post a public plea, requesting insight and guidance, which is then available to the given user's entire network of peers. For instance, an individual might be connected with dozens of people with whom they share a distant psychological proximity (i.e. they are not close, as friends), yet these people could maintain an active presence on the platform, and feel compelled to offer a response. However, if users were able to control who, exactly, would be exposed to an appeal for information, and without jeopardizing existing relationships by neglecting input from their broader community, perhaps the impetus to seek counsel would intensify.

Proceeding from observational research conducted across the web, there is strong evidence to suggest that Facebook's initial charm is beginning to wear off. As seen on social news aggregation and discussion website Reddit, many consumers have taken to the forum to voice concern over Facebook's growing dominance, asserting a number of reasons for abandoning the network. Specifically, its privacy and data mining practices, in addition to how content is served via the News Feed feature. However, upon further analysis, there is one striking commonality among dissidents: a refusal to continue posting on Facebook because of a shared reluctance to disclose personal and intimate details in such a public setting. Moreover, there is a prevalence of largely dormant users who only use the platform for a select few features, including the Messenger function for corresponding with friends, or identifying upcoming concerts and social gatherings through the Events calendar. Because of Facebook's rapid ascendancy and the benefits of network effects, billions of 
people are now registered for the social networking service. Thus, it remains a convenient method of staying in touch and maintaining a line of communication between friends and family. Reddit user coonwiz offered their sentiments, "I have a Facebook, but check it once a week if that. Its [sic] become a glorified event planner. I check it often in the spring to see if I have any grad parties to attend, but other than that it just tells me when people's birthdays are" (Reddit, 2015).

Previously mentioned, the vast majority of disgruntled former users cited Facebook's size as significant deterrent, and the desire to only sustain relations with close, personal friends. For instance, another user by the name of crystalhorsess opined, "I'd just rather not be that connected to people that I don't want to be connected to. The people I want to keep in touch with I will, and if I don't want to I won't"' (Reddit, 2015). Likewise, silent_turtle carried a similar tone, "I don't really care that much about other people's lives. My friends will email or text me, a couple even have conversations with me..." (Reddit, 2015).

To harbour such disinterest in Facebook is not abnormal, as the comments included above are merely a handful of many. On a 2017 episode of the WYNC podcast Note to Self, Brian Feldman, a tech columnist for New York Magazine, lent his thoughts on the matter, which perfectly encapsulates this growing consensus, "I mean, if you look at Facebook-I don't think Facebook is particularly fun to use anymore. I don't really enjoy it. But that is where I can keep in touch with people from high school whose email addresses I don't have. So, you're just sort of locked in to that" (Zomorodi, 2017). Even so, it is not like Facebook is losing its edge and will soon recede from the public's good graces. The network is still experiencing massive growth, having recently surpassed the 2 billion mark in terms of active users (Constine, 2017). The tides are, indeed, turning, albeit not to the 
degree that would dethrone the social networking giant. At the same time, consider the prospects of Web 3.0, where theorists have posited a more open, cohesive, and decentralized Internet-a space that is, to a great extent, governed by the people (Hodgson, 2016). Should the foundational principles of Web 3.0 materialize, and over time, more and more users disaffect from the major networks, there will be a huge opportunity for niche operators to attract and retain new participants. Facebook has devolved into a matter of convenience. Users are locked in, and will likely retain their presence as a means of communication.

\subsubsection{Airbnb}

Another surprising player in the domain of RAD is online marketplace for hospitality services, Airbnb. Since its conception, launch and subsequent adoption, Airbnb has disrupted traditional methods and processes for securing accommodation when visiting a foreign area. Over the years, it is fair to assume that the short-term rental provider has amassed a large amount of rich data, thus supplying management with the insight to make significant improvements to its service offering. In any event, while by no means a focal point of the platform, Airbnb recently introduced a feature where accommodation seekers can now access a list of host-sanctioned recommendations and advice (relative to the area in which the host resides). Airbnb is clearly vying to establish a voice and social standing as a reputable source of destination-specific information, which is readily available to customers upon booking accommodation. Although nascent, Airbnb's new feature lends additional credibility to the value of sound recommendations, and the difficulties consumers face when making decisions in the age of infobesity. 


\subsubsection{Cool Cousin}

Into the bargain, another tool that has emerged in Foursquare's wake is the aptly named Cool Cousin: a mobile application and matchmaking service that pairs travellers with local residents, where the latter assumes the role of unofficial tourist guide. Essentially, Cool Cousin breaks the ice by establishing a relationship between two individuals who would have otherwise never interfaced. However, the actual responsibilities of a designated guide are rather unclear, and can vary depending on the destination. Oftentimes, the 'cool cousin' functions more like a 24-7 helpline than a dedicated chaperone, providing users with critical information regarding matters like transportation services, hospitality, or the operation hours for tourist attractions. The exchange is one-sided, and though Cool Cousin's overarching mission is commendable, ultimately, the information is still originating from an unfamiliar, perhaps even biased source. While the expertise and wisdom of any local inhabitant is, undoubtedly, authoritative, there is no obvious incentive for the individual to provide sound recommendations, much less ideas that are suited to the personal taste and preferences of the information seeker. In this way, the local denizen may harbour a prejudice against certain activities that are perhaps considered enjoyable or popular by most, thus withholding any such knowledge from the holidaymaker. 


\section{Chapter 3}

\subsection{Mobile Application Proposal}

To further explore the merits of eWOM, including its efficacy and major determinants, we will examine how such a behavioural phenomenon coexists with UX, in addition to UI design. Despite lower barriers to entry, still and all, the contemporary marketplace for mobile and web-based applications is decidedly saturated, and thereby inherently competitive. As a result, the role of design has evolved to a point where aesthetics is of cardinal importance; today, realizing success, to a great extent, is contingent on how an application is regarded, visually, by the end user (Creusen et al., 2010). Therefore, exploring the confluence of UX/UI design and eWOM-as well as its driving forces-is of considerable interest to the realm of app development and digital marketing. That is, whether the layout, composition, intuitiveness, and other design elements of a mobile application can influence:

I. The degree to which an individual seeks and provides recommendations with friends, relatives and general acquaintances (i.e. the magnitude of eWOM)

II. The perceived value and esteem-according to the users-of information that is obtained through the platform

III. One's inclination to continue using such a platform, for the purpose of reciprocating experience-based ideas

IV. The incentive and desire to act on a friend/relative's recommendation, taking the appropriate steps to get there

V. The volume of activities a holidaymaker engages in (while abroad) 
VI. Cognitive dissonance, as it relates to travel (i.e. consumer confidence in the decisions they make)

One of the ways in which to further investigate these ideas is through the act of doing. Namely, by gathering the necessary resources and actually designing a mobile application that is expressly built for the exchange of travel recommendations between friends and relatives. A simple, effective and fruitful platform that fosters sociability among people who share a pre-existing relationship, while contributing to the evolution of recommender culture. From here on out, this mobile application and design prototype will be referred to as Dispatch.

\subsubsection{Product Overview}

Dispatch is a lightweight travel application for requesting, storing, and publishing location-specific travel recommendations. Available as a native mobile application, Dispatch aims to synthesize all peer-received travel recommendations into one definitive platform, where users can request advice from friends and family, and, conversely, provide input. Users will be able to review their travel proposals in two formats: in a simple textbased list, with each category clearly denoted, or, alternatively, through a geographical map interface, using Google's API to display the environment. Operating in the crosshairs of a consumer review platform, a social networking service, and a personal travel blog, Dispatch's user environment will capitalize on this newfound dynamic, by offering a mutually-beneficial channel for communicating travel advice with friends and familywhere the end user is significantly more likely to act on the information (Nielsen, 2015). 


\subsubsection{Product Objectives}

Above-mentioned, in Hernández-Méndez et al.'s (2015) report on how eWOM affects the consumer decision-making process in travel, the researchers envision a future where technology can enhance the holidaymaking experience. That is, if providers were to embrace richer, interactive, and more dynamic media-e.g. quality, human-centric designthen it could improve the accuracy of the information that is being exchanged. If any one thing, this is precisely what Dispatch is vying to accomplish: a modernized, retooling of how people seek and provide travel recommendations, designed to circumvent any notion of complexity, affording users with the agency to discover activities by connecting with their peers. Through analysis of past literature, the current media landscape, as well as other, pointed observations, the design architecture of Dispatch will embrace the trappings of successful new media products, while shying away from those perceived as inadequate. It should be noted that Dispatch is, indeed, a proxy, to further explore the virtues of eWOM, and how this behavioural phenomenon coexists with design. Namely, user experience design, and whether an application's look-and-feel can motivate consumers to connect with one another, to share ideas, tips, and advice regarding a particular destination. Lastly, in addition to whether an application's design schema can encourage further use, Dispatch will also propose a revised take on the business model, which incorporates elements from both the traditional and modern approach to revenue generation.

Fundamentally, Dispatch functions as a hybrid tool, comprising elements from social media, OURS, and general communication tools. In a study on pre-trip planning and how the Internet has transformed this process, surveyors were asked to list which platforms they are likely to use when conducting research for a holiday. Generally speaking, 
consumers who are disposed to travel typically seek information from TripAdvisor, various travel blogs, as well as Facebook. This is interesting to note because, for all intents and purposes, Dispatch is something of an amalgamation of the above three resources, thereby encompassing the most popular outlets for obtaining travel information-as expressed by the people (Pabel \& Prideaux, 2016). It offers the intimacy and sociability of Facebook, while fostering location-specific eWOM in the spirit of TripAdvisor, and the sincerity and candidness of a personal travel blog.

\subsection{UX/UI Design Philosophy}

People take great pride and pleasure in offering sound travel advice, and without an application solely dedicated to this kind of user behaviour, Dispatch could triumph through first-mover advantage. However, as a mobile application, the prosperity of Dispatch is contingent on user adoption-which is, undoubtedly, the most daunting obstacle for any new media venture (Chen, 2008). Subscribing to the doctrine of lean methodologies, Dispatch was designed iteratively, where customer feedback was routinely solicited and incorporated, thus following an agile development approach (Blank, 2013). Firstly, the wireframing process encompassed elements from various industry benchmarks, including the aforementioned TripAdvisor, Foursquare, and Atlas Obscura, while patterning other popular social networking tools that are not explicitly geared toward travel and tourism. However, to avoid the pitfalls of a term referred to as feature creep, areas of Dispatch were either stripped down or completely gutted in pursuance of an easy, straightforward, and fluid user environment.

With any mobile product, understanding why consumers delete or uninstall an application is imperative to the development process. Of the countless studies that have 
investigated this phenomenon, there are two elements of particular significance: poor design, cited by 28.6 percent of users, in addition to intrusive advertising, at 41.3 percent (Capita TI, 2016). At the outset, the merits of high-quality and resonant design were contemplated in tandem with the eventuality of monetization, as the application's UX evolved from the confluence of both philosophies; paying equal heed to the two seemingly contrasting approaches was especially important to the development of Dispatch.

\subsubsection{Intended Usability}

All things considered, at the foundational level, Dispatch is a lightweight mobile application, designed to avoid any semblance of intrusiveness. Travel is an experiential form of recreation that necessitates total and absolute presence from the consumer. Should a tourist-centric application command too much of the end user's attention, the fundamental purpose of said application then serves as a direct contradiction to the nature of the activity. Dispatch is of most value to the holidaymaker in the time leading up to a trip-the pre-trip planning stage-where recommendations are requested, consolidated, stored, and referenced at some point thereafter. Although the application promotes sociability within existing friend groups, Dispatch is not intended as tool for round-the clock use. According to a report from Intel (2013) on user engagement, travel applications enjoy a comparatively high rate of retention: 45 percent over the first 90 days post-install. The frequency of use, however, only amounted to circa 2-3 times a week, which perhaps explains why people are less inclined to delete travel apps (Intel, 2013). Howbeit, travel is an uncommon and often sporadic activity that consumers engage in, and makers of mobile applications that service the tourism industry should not expect their products to receive constant and invariable use. Having said that, upon launching Dispatch, user behaviour will 
be closely monitored to identify trends and patterns in usage. Thus, by complying with the manner in which real customers are using the product, management will remain open to further amendments-so long as it aligns with the comportment of Dispatch's active user base (Blank, 2013).

Product

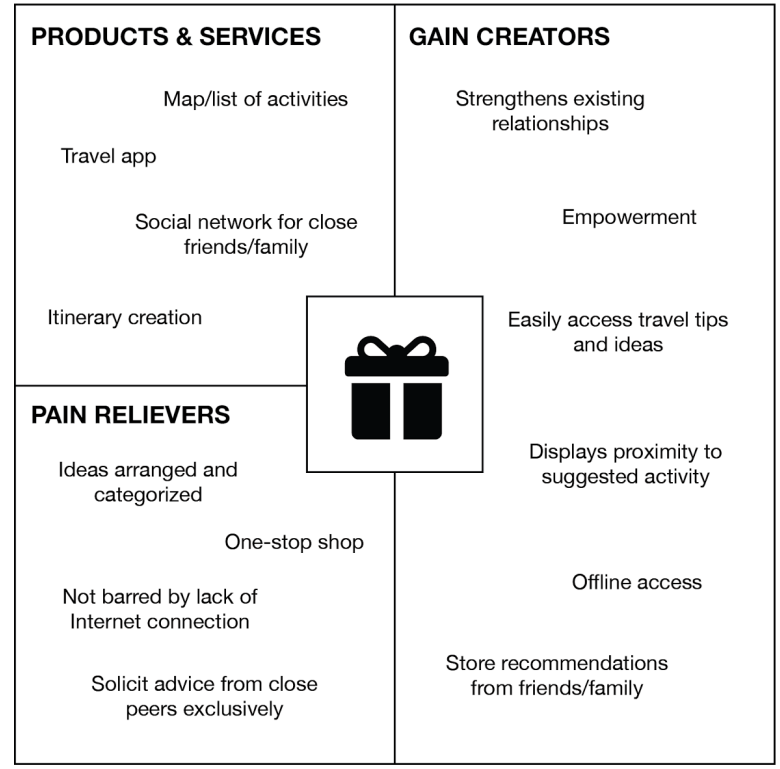

Customer

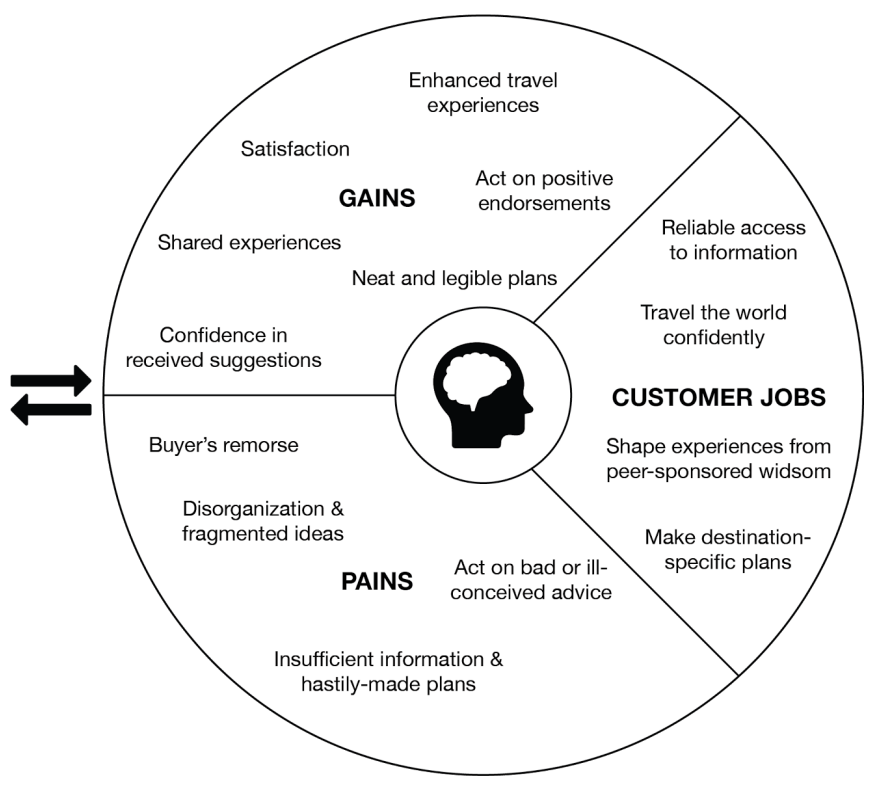

Figure 3.1: Value Proposition Canvas

\subsubsection{Private Network}

Seeing that Dispatch is a mobile application for consumers to engage with those whom they share a pre-existing relationship, users cannot see who other users are connected with (i.e. their list of friends). The logic behind co-opting such a rigid system is to respect the capacity of a recommendation when it originates from a trusted source, and to differentiate Dispatch's offering from that of the competition. Expounded earlier, Facebook users are growing disillusioned with the platform, citing concerns with privacy and data collection, as well as a general apprehension toward the idea of sharing personal 
life details in a public forum. By maintaining a private, intimate network, Dispatch will provide users with a comfortable environment to exchange travel recommendations and parlay advice into real, actionable itineraries. Moreover, in conformity with the literature presented earlier-including Nielsen's (2015) survey on advertising and the unwavering efficacy of WOM-the information received and submitted through Dispatch will be imbued with an unparalleled degree of trust; it is the users who will retain full control over who they connect, relate, and speak with.

\subsection{Core Functionalities}

Getting started with Dispatch is intended to be as effortless and painless as possible. Users can sign up with existing social media accounts through the OpenID protocol-a decentralized authentication system-which includes Facebook, Twitter, and Google Plus ${ }^{6}$. OpenID is widely used method for onboarding new users, as it is compatible with practically all major social media platforms, thus streamlining the registration process by integrating with previously-established contact networks. Alternatively, users can circumvent OpenID and register for an account manually. Further, profile completion obliges the user to provide key details regarding their unique and storied travel history, in order to publicize this information should a close peer wish to seek advice.

6 Although OpenID supports a wide range of social networks, at the start, Dispatch will only allow account creation from the aforementioned platforms; more information on OpenID can be found here: http://openid.net/what-is-openid/ 


\subsubsection{General Overview}

The foremost critical functional that Dispatch performs is the requesting, submitting, and receiving of destination-specific travel recommendations. Considering that Dispatch is a utility product that enables sociability among two, separate parties, the communication protocol will obey a call-and-response approach. For instance, when User \#1 submits a request for advice to second user, User \#2 is notified, and subsequently prompted to provide recommendations. Moreover, once User \#2 has found the time to draft and send a list of ideas, User \#1 is alerted and said list becomes available.

To establish a network of friends and connect with other people, users must provide Dispatch with access to their mobile device's contact list, where they will be able to submit requests. At the same time, users can source contacts from existing social media accounts, such as Facebook, Twitter, or Google Plus, thereby making the process as simple as possible.

\subsubsection{Primary Features}

Regarding usability, the application is divided across four unique sections (hereafter, the "user" refers to the behaviour of one solitary individual as they engage with the Dispatch app):

1. Home

Where the notifications are housed; users can navigate between recommendations that have been received-from external parties, namely friends and family-in addition to requests for advice that were previously submitted by the user, to their peers 


\section{Trips}

A tabulated list that comprises every destination-be it cities, provincial regions, or entire countries-that the user has added to their account; this could entail upcoming trips that have already been booked, tentative plans for a vacation, longstanding desires, or even pipe dreams; should a user click on a destination, they will be able to see the going itinerary, including activity recommendations from friends and family, or ideas manually added by the user; lastly, along with a viewing option, there will be a module for submitting requests for counsel-germane to the destination they have clicked-allowing for a quick and easy method of solicitation

\section{Activities}

In essence, the activities section serves as a repository of information that the user can retrieve and disseminate at any time, for any purpose; in other words, a catalog of their favourite things to do in a particular area, which can be viewed according to destination-that the user is familiar with, be it a hometown or otherwise-in addition to all-time, top picks; this way, Dispatch users can maintain an active record of things to do in a particular area, which can be retrieved, edited, and submitted with little to no effort

4. Me

The user's personal profile, where settings, preferences, and personal details can be managed and edited; additionally, the Me section includes other critical features, like the record of destinations that the user has indicated they are familiar withdenoted as Your Places-thus demonstrating their knowledge and ability to provide quality recommendations regarding the location; other individuals can also peruse 
the user's profile, where they will see the list of destinations said user is wellacquainted with (noted above), in addition to their upcoming trips Further, with reference to the identifying and logging of activities, each recommendation is grouped under any one of the following categories:

- Restaurants and eateries

- Bars, cocktail lounges, and nightclubs

- Coffee and tea shops

- Natural attractions (i.e. public parks)

- Arts, events, and other festivities

- Neighbourhoods and areas to explore (more general)

- Miscellaneous

Situated in the middle of the four above-mentioned menu options lies the New button, which triggers a prompt for the user. This actionable module is available across all sections of the Dispatch application, but its placement in the main navigation bar is to enable swift action, and promote further use. The prompt is broken up into three essential tasks, all of which vital to the chief purpose of the app (see User Flow Diagram, Figure 3.2).

\section{Advice Request}

Permitting the user to quickly submit a request for advice, where selections are made in the following order: the friend who they would like to petition for ideas, followed by the destination they are seeking recommendations for

2. New Activity

For logging a recommendation that is then saved to the user's account-under Activities-whether it is for one of their upcoming trips, or perhaps an idea for a friend; the process of identifying and logging activities-for any given destination-is 
designed to occur not all at once, but over time, as the user either recalls or learns of something; after prolonged use of the Dispatch app, the Activities section will encompass a great many activities for locations all around the world, which can be amended at the user's command

3. Add a Trip/Add Destination

A simple method in which users can include another destination in their list of trips, which is immediately reflected under the Trips section of the app, as well as the user's profile; once a trip is cataloged, the application will ask the user if they would like to begin seeking advice from their network-connected friends, or to shelve such events until a later date

Finally, the remaining module is the Messages hub, which hosts a record of communication that has transpired between the user and their peers. Here, users can initiate and respond to messages, for whatever reason it may be. In today's new media landscape, any application with a social networking component must offer a direct line of communication between the users-an observation noted through the analysis of industry benchmarks, in the domain of travel technology or otherwise. 


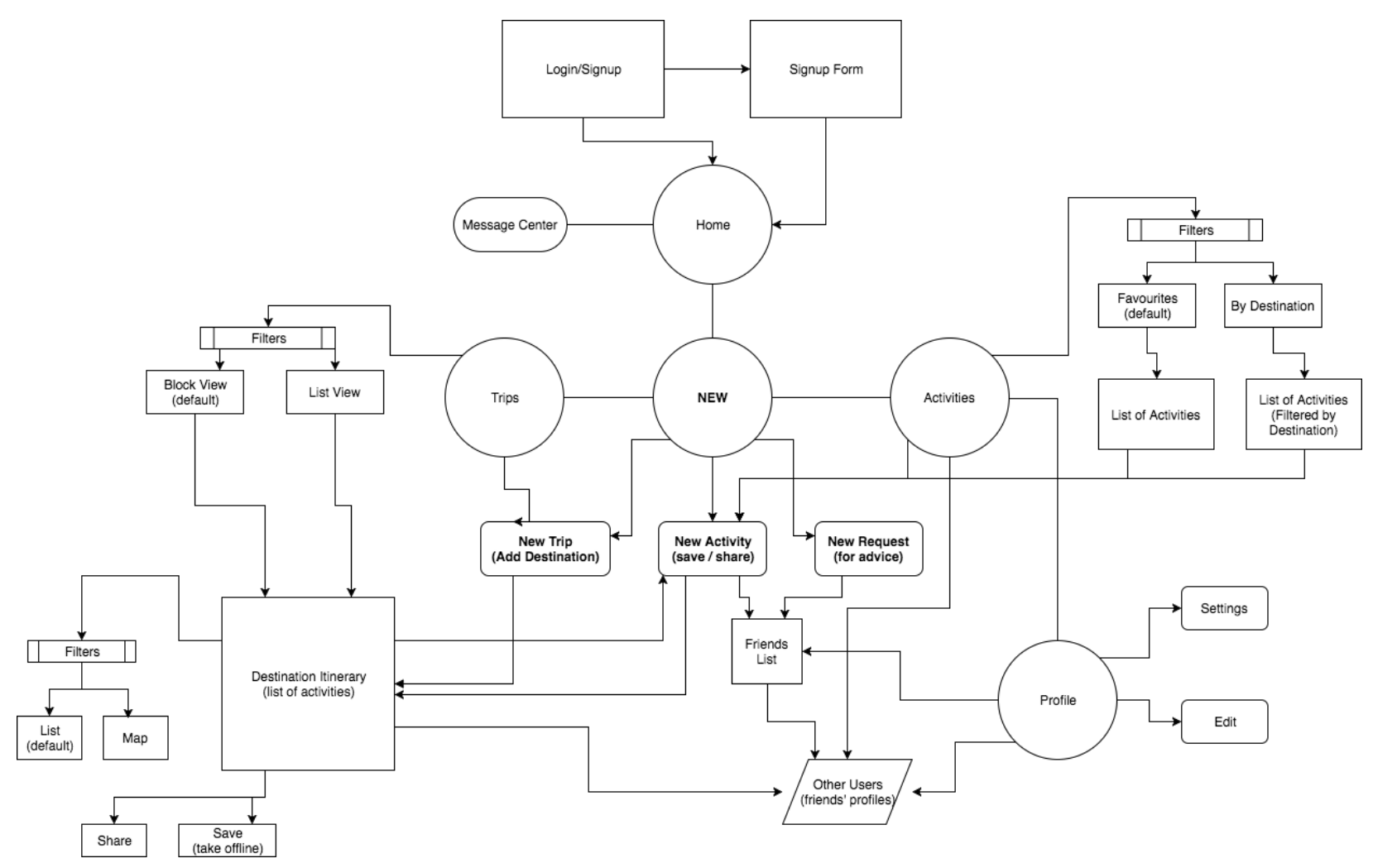

Figure 3.2: User Flow Diagram

\subsection{Peripheral Functions}

\subsubsection{Offline Capabilities}

Mobile devices have become imperative to the travel experience, as consumers strive for a better sense of organization. 72 percent of travellers use their smartphones to find restaurants; 67 percent use mobile devices to identify things to do, and 64 percent for reading reviews on various travel-related establishments (TripAdvisor, 2015). However, in consideration of the modern technological climate, it is fair to assume that while abroad, consumers will likely encounter situations where they are without Internet access (be it for lack of Wi-Fi or data). Although Dispatch's core functionality relies heavily on the web, 
certain components, features, and functionalities will be available in the absence of an Internet connection. Namely, the itinerary or list of activities for a particular geographical region, which the user has sourced from their friends and family. Once a user has received an adequate number of recommendations, a catalog of the items will be automatically saved to the individual's device, thereby taking the content offline, and making it viewable through the application. Alternatively, users can opt to download the itinerary as a textbased list, map, image, or PDF file. The downloaded list of activity recommendations can also be imported to another application on the smartphone, such as iBooks in the case of an iOS device. Ensuring that users can retrieve information that has been sourced through the app is paramount to the Dispatch offering, as travel is unpredictable, and including offline capabilities will only strengthen the value of the product.

\subsubsection{Proximal Notifications}

Assuming that a Dispatch user has solicited advice from a number of friends, the completed itinerary or list of activities is then stored in their account. Upon embarking on the actual trip, the above-mentioned itinerary is saved to the user's profile and is thus readily viewable, even in the absence of Wi-Fi or a data connection. However, while abroad, the user can elect to receive real-time notifications when they verge on the proximity of a suggested activity. True to the nature of travelling, this feature is designed to be a light and un-obstructive reminder, solely for the purpose of enhancing the holiday experience. For instance, consider this hypothetical scenario: a user who is currently travelling in Victoria, British Columbia, has chanced upon a particular neighbourhood called Fairfield. Now, having come within a few kilometers of a pizza restaurant that a friend has recommended, 
the user receives a notification, informing them of the activity, as well as the individual who provided the idea.

\subsubsection{Passive Recommendations}

Observing the research of Duffy (2015), in addition to Cheung et al. (2009), Dispatch will incorporate select elements that are typically found in OURS, thereby remaining agile and affording greater strength to the application. Although much less credible, there are certain aspects of OURS that aid and abet the efficacy of a recommendation. Crossreferencing, firstly, is a tremendously useful tactic employed by Internet users to support the decision-making process: 42.3 percent say after consulting one source, they compare, confirm, and corroborate the information against another site (Duffy, 2015). As a result, on Dispatch, when an activity is recommended to a user, there will be a secondary, initiallyhidden component to the recommendation, which comprises a metric that represents its popularity and frequency. Like so, despite the information coming from a trusted sourceand personalized to the recipient's taste and preferences-it is furnished with an additional layer credibility, thanks to the virtues of normative influence (Cheung et al., 2009). Moreover, such recommendations will always adhere to the passive form, using phrasing like "other users have also visited," as people are generally more receptive to this style of language (Hamari et al., 2017).

\subsection{Business Model}

Any plans to monetize the platform will only come to fruition once Dispatch has garnered and retained a substantial base of active users. Even so, incorporating any such

revenue-driving policies will be executed over time, and with considerable prudence, thus 
ensuring that the Dispatch UX remains intact. As a consumer-oriented product, there are no upfront costs associated with Dispatch, as the application will retail for free. As numerous studies have indicated, by making the application available for free, Dispatch will receive significantly more downloads upon launch (Delgado, 2017). Thus, Dispatch is fulfilling the role of a publisher, pursuing an indirect monetization strategy that is more in line with an app-based, social networking product (Chen, 2008).

The application's main sources of revenue will derive from the following activities: branded takeovers, native advertising, premium usage, partnerships and specialized vouchers, as well as data analytics and customized reports (available to interested businesses). Evidently, there are no plans to integrate a tool for booking transportation or accommodation. This is because Dispatch is not intended as an affiliate service that connects customers with other merchants, but rather, a mutual avenue where trusted parties can exchange ideas and guidance. Further, omitting such functionality also serves to differentiate the application's core offering and usability, which strengthens the Dispatch value proposition.

\subsubsection{Branded Takeovers}

Select companies will be identified and petitioned to procure an application-wide placement, which involves the temporary replacement of Dispatch's core branding. Based on observational research across the web, branded takeovers are a burgeoning vehicle that brands have adopted to reach new audiences. Moreover, the scope and intensity of the takeover varies from platform to platform. For instance, consider IMDb, which is an extremely popular online website and database of films, television shows, and video games. An early pioneer of branded takeovers, when IMDb works with a studio to promote an 
upcoming film, the design of the given film's IMDb page will be completely overhauled, to align the colours, aesthetics, and tone with the appropriate branding scheme. Additionally, IMDb will incorporate rich media, such as custom-built marketing materials or exclusive interviews with cast. In the spirit of IMDb, Dispatch will consider producing special, original content for interested brands to further campaign efforts and elevate the tenor of the messaging. Conversely, there will be other, smaller-scale, and more affordable takeover options available to brands. By way of illustration, the Internet's foremost microblogging platform, Twitter, will often team up with brands to incorporate various materials into its UGC. For example, when a user publishes a Tweet that comprises a certain brand-related hashtag, the post will be accompanied with a custom-made emoji, which is germane to said brand. Thus, the breadth of each campaign will be conditional on the participating company, their objectives, and marketing budget.

\subsubsection{Native Advertising}

Advertisements will be served natively, as a list item recommendation appended to an itinerary. Over the next half-decade, global spend on in-app advertising is expected to mushroom from USD $\$ 13$ to $\$ 52$ per user, where a greater emphasis is placed on targeting and location specificity. (Delgado, 2017). Naturally, advertisements are to be implemented delicately, and, in the beginning, sparingly, to ensure that the application's overall UX remains unchanged. Further, the messaging will embrace language that does not address

the user, directly, to avoid over-personalization. Therefore, advertisements will be couched in the passive form, such as "other travellers have..." or "this is the most popular..." (Hamari et al., 2017). Remuneration is contingent on the brand, its scale, reputation, and campaign objectives. Deals will be established well in advance, thus affording enough lead time for 
both parties reach a satisfactory agreement. However, rates are to be tied to performance, which is congruent with accepted practices and compensation models in Internet advertising. Namely, cost-per-click (CPC), where the publisher (i.e. Dispatch) earns a fixed amount for every click an advertisement receives, as well as cost-per-thousand (CPM). The latter, CPM, is similar to CPC, but remuneration-which is also a previously-established, fixed amount-occurs for every 1,000 times an advertisement is seen (i.e. impressions). Moreover, other compensation models will also be considered in future iterations of the product, to ensure that Dispatch remains agile and open to alternative means of income.

\subsubsection{Partnerships and Specialized Vouchers}

With a focus on small and medium-sized businesses, through Dispatch, users will be able to obtain special voucher coupons and discount codes that are redeemable at participating merchants. That is, in the event that a user receives a recommendation to visit a particular establishment, which Dispatch has already formed a partnership with, thereby assisting, not forcing, the experience. As a result, travellers will save additional money, while, at the same time, businesses can service more clientele. Managing this agency-like arm of the Dispatch application is likely to pose many challenges, as onboarding businesses, working out deals, and executing campaigns will require considerable diligence. However, from the outset, any such activities will not be pursued, seeing that the product-and its inherent quality and value-is of prime concern. That being said, during product development, the necessary groundwork will be laid to enable a simple and efficient method in which interested merchants can promote special offers. More specifically, an automated marketplace that connects businesses with potential customers who have already been informed of said business' offering. 


\subsubsection{Premium Usage}

Should the aforementioned marketplace for discount offers come to fruition, it would be most advantageous for Dispatch to provide another layer of usability. Implementing such systems has become common practice; for instance, there is Facebook Business and Ads Manager, LinkedIn Premium, and, most appositely, Zomato, which currently manages two unique applications: one for regular, everyday consumers, and another for merchants. At any rate, if a need is recognized, Dispatch will incorporate another tier of usage, whereby merchants can unlock a number of additional features and functionalities.

In accordance with Zomato, the merchant account would be accessible through a separate, freemium application. Once the business has completed registration, which involves a verification process, they can then review, manage, and edit the details of their unique page. However, to unlock additional features, such as the above-mentioned marketplace for promoting specialized vouchers, the merchant must pay a monthly subscription fee. With reference to Zomato, the web service does not publicize its subscription rates, as the monthly sum is not fixed, but relative to the size and nature of the participating business. However, several online publications have indicated that Zomato charges merchants as much as USD \$200.00 per month for a white label account ${ }^{7}$. Thus, Dispatch will establish different tiers of premium usage, to accommodate businesses of all size: small, medium, and large, which are to retail at a monthly fixed rate of USD $\$ 35.00, \$ 65.00$, and $\$ 100.00$, respectively.

\footnotetext{
${ }^{7}$ Monthly subscription figure of USD $\$ 200.00$ was obtained from The Next Web, which can be retrieved at: https://thenextweb.com/apps/2015/09/07/zomato-makes-it-easy-for-every-restaurant-to-have-its-own-app/
} 
Businesses with a Dispatch merchant account will gain access to the following features: tools for creating and promoting specialized vouchers, native advertisements, as well as access to relevant data and statistics regarding its performance on the application (to be expounded below).

\subsubsection{Data Analytics/Customized Reports}

Dispatch will market bespoke data reports to merchants that are seeking a broader understanding of customer activity and brand engagement. As Dispatch users create itineraries and exchange recommendations, the application will regularly collect data that can be extracted, packaged, and delivered to businesses that are interested in learning more about their eWOM performance. What's more, in regard to the very essence of eWOM, businesses are virtually powerless, and cannot directly influence what is being said about them online. Because of this vulnerability, the only feasible method in which businesses can foster positive eWOM is by focusing on their core competencies and optimizing where necessary, ergo functioning at the highest standard possible. Examples of relevant metrics include: total number of recommendations submitted, a performance index that reflects the overall popularity of the business (e.g. "4th Most Recommended Cafe in Victoria, British Columbia"), and a fulfillment ratio, which comprises the number of users who carried out an activity divided by the sum of all recommendations (e.g. 120 users acting on 300 recommendations submitted, equating to 0.4 or $40 \%$ ). Evidently, the greater the fulfillment ratio, the better a business is performing. 


\subsubsection{Exit Strategy}

Seeing that Dispatch is to monetize indirectly, as a publisher, with a concentration on building an audience and platform scalability, it is in the application's best interest to have an exit strategy in place (Chen, 2008). In the eyes of potential investors, publishers are generally perceived as riskier endeavours, but when executed well, are capable of producing massive returns. By marketing the product for free, consumers have nothing to lose, and are thus more likely to download the application. Needless to say, success is entirely contingent on the product, and if it can actually provide something that is perceived as genuinely useful and easy-to-use by the end user (Davis, 1989).

Should Dispatch penetrate the cultural zeitgeist and realize substantial growth, it is fair to assume that the application will attract outside attention, from investors, venture capitalists, businesses, or otherwise. Under these circumstances, any such opportunities will not be sought out, explicitly, but taken into consideration. That is, if the opportunity is congruent with the Dispatch mission, and is deemed to be value-adding, regarding distribution, product and technical capabilities, or other functions of the application.

\subsection{User Acquisition Plan}

The underlying objective of Dispatch's marketing plan is to communicate the app's genuine usefulness and ease-of-use, thus obeying Fred Davis' (1989) time-tested principles of the technology acceptance model. Further, in view of Dispatch's primary function-that is, to facilitate eWOM between friends and family-creating demand for the product will follow the same approach. A user cannot derive any value from the application without input from another, fostering an environment where network effects can take shape. 
However, despite the proposed value of eWOM, it is ultimately contingent on satisfying one, all-important criterion (which hearkens back to Davis' [1989] theoretical framework): product quality. Thus, Dispatch will be operated in the spirit of lean startup, where customer feedback is routinely adjured, ensuring that product development is continually informed by the end user (Blank, 2013).

Initial marketing efforts will embrace a diverse range of modern, Internet-oriented tactics, further complemented by the product's inherent attributes. Customer acquisition remains the top priority, as Dispatch needs to accumulate at least 100,000 app downloads before implementing any monetization strategies ${ }^{8}$.

\subsubsection{Target Market}

Dispatch is primarily geared toward 18 to 34 year olds who are technically savvy, active on social media, and disposed to travel. Further, as Dispatch's user experience is designed to be as simple and effortless as possible, the application will also cater to a secondary audience: Baby Boomers. Aged between 52 and 70, this demographic is largely composed of retirees (or soon to be), who are comfortable, financially, and have a strong desire to have authentic travel experiences ${ }^{9}$. Relatedly, while not as adept with technology, this generation is also known for sharing similar travel behaviours with the younger demographic (ITB Berlin, 2016). Thus, in order to appeal to this older, more technophobic audience, Dispatch's usability must avoid any semblance of a learning curve.

\footnotetext{
${ }^{8}$ Estimate derives from Google AdMob, an online toolkit to assist with monetization; app developers can only schedule a free consultation once the platform has received 100,000+ downloads: https://www.google.com/admob/

9 Age range estimate was obtained from a 2016 Pew Research Center report, which can be retrieved at: http://www.pewresearch.org/fact-tank/2016/04/25/millennials-overtake-baby-boomers/
} 


\subsubsection{Positioning Statement}

For the modern-day explorers, the adventurers, and globetrotters, Dispatch can enrich your travel plans through the wisdom of your nearest and dearest. See the world with a little help from your friends.

\subsubsection{Distribution}

In the first few months upon launching the product, Dispatch will be an invite-only social network. Such a release strategy is designed to execute two, critical functions: Create demand through scarcity and exclusivity, and establish a controlled user environment, where bugs and other kinks can be resolved prior to a wide release. To reach as many potential users as possible, Dispatch will be available through all major app marketplaces. Namely, the iOS App Store, Android's equivalent, and Google Play.

\subsubsection{Promotion Strategy}

In an effort to attract users and promote brand awareness, Dispatch's communications strategy will incorporate both inbound-content, social media, search engine optimization-and organic marketing tactics. Through a narrative-driven, contentbased strategy, Dispatch will work with publishers to deliver a consistent and compelling message across a myriad of channels. Moreover, with respect principles of WOM, the Dispatch app is equipped with a number of tools for self-expression, where users are encouraged to share their creations with whomever they like. According to a 2016 consumer report from Google, the top method of app discovery is through friends and relatives who are already using the product, which accounted for 51 percent (Google, 2016). Per a combination of inbound and organic tactics, the Dispatch team will work tirelessly to 
mitigate spend while maximizing reach. Regarding the application's go-to-market plan, it is best described as a series of activities, managed through a cyclical approach:

- Website/landing page that houses marketing content

- Earned media, by connecting with relevant journalists and soliciting press coverage

- Community engagement, through various online forums

- Reporting and performance analysis, to identify which areas are producing the best results; customer feedback

\subsubsection{Content Marketing}

Regularly publish blog posts, not always germane to Dispatch, but the application's target market; that is, topics related to travel, technology, and digital marketing. Other examples of written content include guest posts, opinion pieces, product reviews, how to guides, case studies, testimonials, and list-based articles. Moreover, Dispatch's content strategy will also comprise alternative forms of communications, rounding out a multiplatform, transmedia narrative, including: video, infographics and, eventually, a podcast series, all of which documenting an individual's journey as they travel around the world, from one country to the next, engaging in activities that have been prescribed by their friends and family. It should be noted that any piece of branded content will be consistent-in terms of aesthetics and tone-with the Dispatch brand, embracing the same colours, typography, design scheme, and language.

\subsubsection{Community Engagement}

Create and manage profiles on a handful of community-rich social networks, like Quora and Reddit. For Quora, specifically, questions that are analogous to Dispatch's core 
themes will be answered, providing intelligent, meaningful, and practical information. Moreover, using 5-10 keywords that are relevant to the Dispatch brand, a series of Google searches will be conducted to uncover online communities where additional engagement could occur. Assuming that the consumer review forum is credible, and enjoys regular discourse and user traffic, Dispatch operatives will contribute to discussions, offering different perspectives, and stimulating conversation.

\subsubsection{Earned Media}

In lieu of retaining the services of a public relations (PR) firm, Dispatch will handle all of its PR in-house. The basis of Dispatch's PR efforts will comprise the efficacy of WOM and eWOM, how RAD is shaping the future of travel, as well as the growing skepticism around traditional advertising. Further, the application will be touted as the very first RAD tool, where the act of searching is of secondary importance.

\subsubsection{Customer Feedback}

In addition to the above-mentioned tactics, management will be regularly communicating with Dispatch's inaugural user base to assess their attitudes, judgments, and ideas, and synthesize these findings with product development. Often described as a customer feedback loop, by adhering to this lean methodology, improvements to the Dispatch platform can be made in a timely and cost-effective manner. Maintaining a consistent and healthy dialogue with Dispatch community will remain a top priority throughout all stages of the venture. Likewise, by establishing a sense of trust, Dispatch operatives can also enable a mutually-beneficial framework for identifying weaknesses and building upon existing features-users will, undoubtedly, be receptive to an update if it was their idea in the first place (Blank, 2013). 


\subsubsection{Organic Tactics}

The essential qualities of the application command an environment where users must consult one another, to exchange ideas, tips and advice. Thus, assuming Dispatch is, indeed, a valuable product, users should flock to the platform by way of network effects. What's more, is Dispatch's primary function as a social media tool; that is, to create itineraries based on recommendations. Once a user has collected a list of activities pertaining to a certain area, said list can be exported, embedded, or shared on external platforms. In sum, all UGC from Dispatch, is, by nature, shareable. Thus, should someone feel inclined to share an itinerary-whether it is their own ideas, passed on to a friend, or a list of activities they have received from other people-Dispatch will make it as easy as possible.

\section{Chapter 4}

\subsection{User Testing}

Prototyping the application commenced in December 2016, beginning with a user flow diagram, which provided a more holistic view of the UX journey. From April through June of 2017, three iterations of the Dispatch design prototype were built, and ultimately completed prior to July. The application's eventual design was informed by the research expounded above, including past literature and industry reports, as well as a review of industry benchmarks that are currently on the market. However, without the input and feedback of real, everyday people-who embody the traits of the application's target segment-the product's viability would remain uncertain, and thus unvalidated. Moreover, 
in adherence to the lean startup methodology, this current rendition of the product is simply just another iteration; one of many builds that will undergo additional testing in the future (Blank, 2013).

\subsubsection{Development Background}

To create the air of a functioning application, the prototype was largely constructed using JavaScript, an object-based programming language that imparts a high degree of interactivity. For instance, the ability to drag, drop, and sort list elements that are included in a particular itinerary. Additionally, through JavaScript, each section of the application could be included within the same page, enabling a smooth and continuous navigation process that is bereft of loading, lagging, or freezing. When a user taps on a menu item, the information is not requested from the server, but its appearance is toggled, from hidden to visible. Moreover, by structuring the content hierarchically, the JavaScript could be composed using relational selectors, which monitors user flow and simplifies the navigational process. In other words, should the user travel to a subsection of a certain page, a back button-based on the navigational lineage-would come into view. Thus, if tapped, the user would revert back to the section from which the subsection resides under.

\subsubsection{Testing Environment}

Due to time and budgetary constraints, participants were recruited through opportunity sampling, which was the most convenient and affordable option. The 15 individuals who composed the testing group were deemed adequate representations of Dispatch's target market; namely, 18-34 year old consumers who are both predisposed to travel and technically savvy, as well as a handful of Baby Boomer, aged 52-70, who 
constitute Dispatch's secondary market. As expected, because the participants were gathered in this manner, any insights gained through testing are susceptible to bias, and thus, not totally objective. Howbeit, subjects were instructed to speak candidly, and to disclose as much or as little information as they would like.

Apart from the presence of a testing administrator, each participant engaged with the application in solitude. This arrangement allowed for a more controlled testing environment, where the subject's remarks could be recorded with greater accuracy, and without the hindrance of outside opinion.

Table 4.1: Participant Demographics

\begin{tabular}{|l|c|c|c|c|}
\hline Age Range & Number of Males & Number of Females & Total & Total (\%) \\
\hline $10-17$ & 0 & 0 & 0 & $0.00 \%$ \\
\hline $18-34$ & 4 & 4 & 8 & $53.33 \%$ \\
\hline $35-51$ & 2 & 0 & 2 & $13.33 \%$ \\
\hline $52-70$ & 2 & 2 & 4 & $26.67 \%$ \\
\hline $71+$ & 0 & 1 & 1 & $6.67 \%$ \\
\hline Total & 8 & 7 & 15 & $/$ \\
\hline Total (\%) & $\sim 53 \%$ & $\sim 47 \%$ & $/$ & $/$ \\
\hline
\end{tabular}

The number and gender of subjects who tested the application.

Running Dispatch on a 2015 iPhone SE, participants were invited to use the application and make comments at their discretion. The administrator prefaced the test with a brief overview of the app, explaining its fundamental purpose, as well as the context in which such a tool would be of most value. Questions were fielded on an ad hoc basis, typically to provide additional clarity, or to notify the subject of additional features. 


\section{Chapter 5}

\subsection{Results}

Welcoming participants to use the Dispatch prototype yielded several valuable insights, most of which pertaining to its features, UX/UI, applications, and outside

potential. Virtually all of the subjects were enthused by the idea, touching on various instances where they had either requested or provided travel recommendations to a friend or relative. Likewise, in the younger demographic-approximately 18-34 years old-many of the participants lauded Dispatch's simplicity and ease-of-use, understanding its chief purpose and envisioning future scenarios where they could employ the app.

\subsubsection{User Feedback}

Perhaps due to the informal nature of the testing environment, howbeit, much of the feedback comprised ideas to further enhance the application. One individual, Donald (25, male), yearned for category filters when viewing an itinerary or catalog of activities, to better refine the contents of a list. For example, a drop-down menu where the default option is "All," but, should the user select "Restaurants," the items listed below would only display food-related recommendations. Another participant, Julia (24, female), indicated a desire to connect with other users through a mutual friend. That is, to facilitate a correspondence between two users who she is well-acquainted with, but do not know each other, personally. This notion had been explored during the ideation process, but it was ultimately dropped in pursuance of simplicity. However, as more individuals tested out the Dispatch app, many of the subjects voiced ideas that were along the same lines. Enabling 
users to serve as the intermediary between two, other users would go against the very fabric of the application. After all, Dispatch is only supposed to cater to those who share a pre-existing relationship. Having said that, due to the high-volume of participants who expressed interest in such a feature, perhaps Dispatch should pander to the demands of its prospective user base.

In addition to connecting with other users on the basis of a mutual friend, a handful of test subjects proposed another, similar idea: the capacity to follow tastemakers. Chris (40, male) voiced an interest in being able to compare recommendations against the guidance of a popular travel blogger, or a celebrity who is familiar with the area. By way of example, Chris envisioned a trip to New York City, where he could source travel tips from friends and family, while also being able to see what other notable figures have recommended. Alessandra (19, female) conveyed a similar desire, but in a more nuanced fashion: In lieu of soliciting famous personalities to register for an account and create fullbodied itineraries, Alessandra suggested nominating one notable figure per every major city, who then serves as an unofficial tourist guide. As the de facto ambassador, the individual would provide one recommendation-pertaining to any category-that is tentatively assigned to the area. Thus, if a user were to add a trip to their profile and begin requesting ideas, the ambassador's recommendation would be a prescribed element of the itinerary, displayed as an appended list item. Relatedly, Guillermo (37, male) posited that every unique page for a major destination should have a section that comprises itineraries or list of recommendations that were curated by tastemakers. Should a Dispatch user peruse the application, looking at various cities around the world, they could discover content from famous individuals who they do not know on a personal level, but perhaps admire. 
To the point above, enabling this expanded degree of usability would grease the wheels for an entirely new form of branded content. For instance, enlisting famous personalities to create annotated itineraries or list of recommendations, discussing their favourite things to do in a particular city, which are then viewable on the Dispatch platform. The content is original, and produced by the celebrity to, perhaps, bolster marketing efforts for an upcoming project. The list of recommendations is clearly denoted as a piece of sponsored content, with the messaging indicating what is being promoted. However, because of the tastemaker's dense following and likeability, the information would ultimately be perceived as valuable, because it is both entertaining and enlightening. Moving forward, in the event that Dispatch is well received and the application experiences consistent growth, the ideas stipulated above will be strongly considered, but not outright pursued. Above all, Dispatch is intended to epitomize the principles of RAD; straying too far from its intrinsic qualities might detract from the novelty of the application.

A large number of subjects inquired about the application's compatibility with other, popular social networking platforms. Specifically, Snapchat and Instagram, and whether or not there were plans to integrate outside content, either through a partnership or the relevant API. This sentiment was often brought up by the younger participants-aged between 19 and 25 years old-who admitted to being active on the aforementioned social media. Generally speaking, while these test subjects were enthusiastic about the product, many acknowledged the importance of visual content, and how they are typically drawn to applications that encompass pictures, videos, and, in one case, cinemagraphs. The significance of visual content in the current media climate is well established; for example, Facebook posts that include an image perform 2.3 times better than those without, leading to more clicks and higher levels of engagement (Mawhinney, 2017). Relatedly, early 
iterations of Dispatch comprised a content feed, where all images, videos, and status updates posted by a user and their network-connected friends would be displayed in one, dedicated area that is readily accessible through the navigational menu. This feature was ultimately abandoned to concentrate the UX around the providing and requesting of travel recommendations, thus maintaining the intimate nature of the application. Besides a content feed, there are other methods in which visual material could be employed. Anthony (22, male) further corroborated the growing efficacy of video; as an avid photographer and videographer, Anthony creates video portraits of various destinations around the world, which he publishes across a range of online channels, including YouTube, Facebook, Twitter, and Instagram. In his words, the videos are designed to accentuate the greatest qualities of a particular city, instilling pride in its residents, while appealing to potential visitors, and contributing to ongoing tourism efforts. By way of example, Anthony used his craft to communicate the merits of well-produced video, advancing an idea to supplement the application's usability: create a unique listing or page for every destination around the world, including an array of rich media, which is sourced from the community, and curated by the Dispatch moderators. Looking ahead, as users adopt the application and begin producing content, ultimately, Dispatch will host a dynamic inventory of the world's numerous destinations. During this process, it is conceivable that each listing could be systematically built out, leveraging the profusion of UGC to improve the digestibility of the information.

To the point above, in the event that a user follows a recommendation through, said user would likely yearn for the ability to share the experience with whomever provided the original idea. Moreover, if additional users were to act on the same recommendation, Dispatch could house a record of each occurrence, where all contributions-be it pictures, 
videos, or status updates-are presented in a gallery, and organized by the upload date. Over the long haul, this body of content would amount to a comprehensive media library, shared among the users who have contributed to it-put simply, a perennial logbook of travel experiences. At present, the Dispatch application is largely composed of text-based content. Henceforward, product development will conform to the demands of the user, in addition to the existing state of affairs, and make the necessary provisions to include more visual content.

Offline performance was also a prime concern for many of the participants. That is, its ability to access certain information in the absence of an Internet connectionsomething that has been accounted for in the initial development cycle. Further, Marie (60, female) expressed an interest in allowing non-users to contribute recommendations, should they not possess a mobile device, or a desire to download the application. Her idea is to provide a web-based alternative, where users can invite friends and family memberswho are non-users-and source recommendations through a permalink. As a selfproclaimed technophobe, Marie opined that such a feature would likely appeal to other people in her age group, as they are more comfortable providing information from a computer versus a smartphone.

\subsubsection{Reflections}

Concerning the type of feedback received, one theme emerged: While the vast majority of participants were enthusiastic about the application, many expressed reservations about its exclusivity (i.e. how users can only relate with close friends/relatives). As noted above, during the design process, this approach was taken to distinguish Dispatch from other travel apps, and to harness the efficacy of eWOM 
recommendations that are shared between friends and family. Nevertheless, heeding to the principles of the lean startup methodology, user feedback will both be addressed and incorporated into the next stage of the product's development (Blank, 2013). In doing so, the ability to connect with people outside of the user's immediate social circle will be available, but not emphasized. In other words, a secondary, peripheral feature to rectify demand, but not detract from Dispatch's chief purpose: to facilitate the exchange of experienced-based recommendations among people who share a pre-existing, close relationship.

In regard to the confluence of UX design and eWOM, and how the two elements coexist, half of the above-stated objectives could be supported through user testing. The evidence in favour of these assumptions were drawn from comments, utterances, and offhand remarks that were provided by those who engaged with the Dispatch design prototype. Of the six objectives proposed earlier, four were deemed to have substance, which will be expounded below.

Table 5.1: Outcome of Research Objectives

\begin{tabular}{r|l|c|}
\hline & Assumption & Supported (Y/N) \\
\hline I. & $\begin{array}{l}\text { The degree to which an individual seeks and provides } \\
\text { recommendations with friends and relatives }\end{array}$ & Yes \\
\hline II. & $\begin{array}{l}\text { The perceived value and esteem-according to the users-of } \\
\text { information that is obtained through the platform }\end{array}$ & Yes \\
\hline III. & $\begin{array}{l}\text { One's inclination to continue using such a platform, for the } \\
\text { purpose of reciprocating experience-based ideas }\end{array}$ & Yes \\
\hline IV. & $\begin{array}{l}\text { The incentive and desire to act on a friend/relative's } \\
\text { recommendation, taking the appropriate steps to get there }\end{array}$ & No \\
\hline V. & The volume of activities a holidaymaker engages in & \\
\hline
\end{tabular}




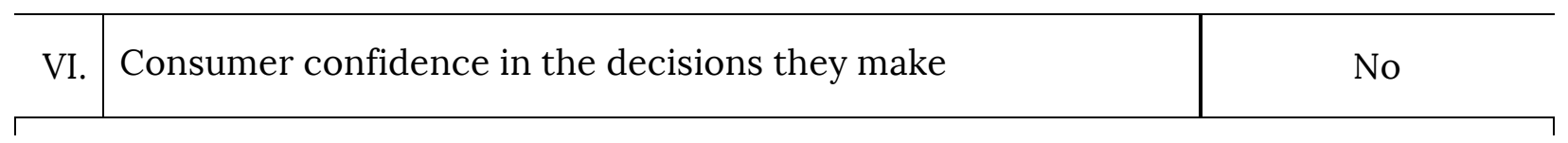

Question: Can the overarching design of a mobile application influence(?):

As alluded to earlier, virtually all of the participants indicated that having access to a tool such as Dispatch would improve the likelihood of them exchanging travel recommendations. Further, because of application's straightforward design schema, and how each piece of advice is automatically tabulated, many of the test subjects communicated an interest in using the application before and during their next trip. On top of continued use, the UX and UI made participants feel as though they would try harder to follow through on each recommendation, which can be attributed to its legible format. Once more, due to the leisurely testing environment, for what reason, exactly, is unclear. However, several individuals did make note of the application's ease-of-readability, offering praise for its tidiness, as it relates to the style in which the information is presented. In whatever way, there was insufficient evidence to validate the remaining three objectives. Assessing the value of the information-as perceived by the user-would necessitate a more comprehensive study that is commissioned over a longer period of time. Similarly, measuring both the volume of activities that a traveller partakes in, as well as consumer confidence was not possible through user testing. In the interest of substantiating these assumptions, ultimately, the product will need to be tested by consumers while they are travelling abroad.

On the whole, the product was exceptionally well received, as participants were excited about the prospect of such an application. Moreover, the product's design was also praised by the test subjects, both aesthetically as well as its ease-of-use. Again, due to the 
informal testing environment, whether the participants were responding truthfully or sincerely is not known. However, as mentioned above, the majority of subjects could foresee the value of having such a product, while meditating on other, possible use cases, and inquiring about its availability. In pursuance of market validation, though, the Dispatch application will have to endure further rounds of testing, which should take place over an extended period of time, and encompass a larger sample group. Lastly, of those who are elected to participate, half would be required to stay behind, while the rest travel abroad, thus precipitating a more authentic testing environment.

\section{Chapter 6}

\subsection{Implications}

Through secondary and observational research, coupled with the ideating, designing, and testing of a mobile application, a number of key takeaways have emerged, which will be expounded below. Any manager, enterprise, or onlooker in the new media space that is concerned with information discovery-and how the process is evolvingshould reflect on these summations, as it extends far beyond the realm of travel.

\subsubsection{Comfortability Yields Activity}

Regarding Hernández-Méndez et al.'s (2015) analysis of eWOM in travel, one of the study's primary objectives was to discern the extent to which consumer use different travel websites and review forums to both obtain information and post about their trips. Interestingly, of those surveyed, 66 percent claimed to have never published or shared 
their experiences on these sites. On the contrary, 34 percent of Internet users have, indeed, posted about their travel experiences, albeit on a personal website or blog. The study also found that when a consumer is acclimated to a particular online platform, they are more likely to produce and share content. Thus, one can deduce that an Internet user is most comfortable posting about their experiences abroad when they feel a sense of ownership over the environment. Through comfort, consumers find confidence, and under such circumstances, are significantly more motivated to disclose their personal opinions. Comfortability is difficult to achieve in large-scale, all-encompassing networks such as Facebook and TripAdvisor, thereby presenting an opportunity for niche, intimate platforms where users can securely discuss their experiences.

\subsubsection{The Enduring Power of Normative Influence}

Cheung et al. (2009) indicate that operators of eWOM forums should concentrate on how to improve information quality, as well as source credibility and reputation. The researchers postulate two methods in which this could be achieved: by improving the design and functionality of the tool, with sharper aesthetics and stronger performance. Additionally, Cheung et al. (2009) also suggest better systems for promoting normative influence, through rating aggregators, product and service review filters, and other metrics that reflect consistency of opinion. Both of these ideas can be rectified under the principles of RAD, as information quality and source credibility is never a concern, and will not be marred by doubt. Consumers have and will continue to trust the attitudes, judgments, and beliefs of their close friends and relatives, because of psychological proximity, and a strong presence of homophily (Bonezzi et al., 2016; Duffy, 2015). Further, observing the efficacy of aggregated opinion as found by Cheung et al. (2009), along with the feedback received 
through user testing of the design prototype, Dispatch, one can surmise: Despite the proposed intimacy of RAD and networks that embrace its tenets, still and all, designers must include the requisite functionality to foster a sense of normative influence. This notion was initially overlooked in the development of Dispatch, but future builds of the product will now account for these findings, thereby satisfying market demand-in adherence to past literature and the feedback received from user testing.

\subsubsection{Looking Beyond Search}

The act of searching is likely to change over the coming years, as consumers look to speedier, more dependable processes for discovering information. Already, the practice of search engine optimization has experienced a number of overhauls; in an effort to accommodate the growing efficacy of localized search, as well as the use of natural language to construct search terms, and voice control commands like Apple's Siri or Amazon's Alexa (Monago, 2015). People tend to migrate toward technology that better suits their behaviour, thus signalling a need for more human-centric design (Hodgson, 2016). Consequently, while search will remain at the forefront of how information is retrieved through digital means, other variations on the task are sure to crop up. Most notably, however, is the aforementioned RAD, which pairs one consumer with another, to exchange experience-based recommendations that are germane to the receiver's personal taste, preferences, and attitudes.

\subsubsection{Shaking the Habitual}

Originally conceived in the aftermath of infobesity, by design, Dispatch will herald a new paradigm, where Internet users curtail their search habits in favour of connecting with 
and relating to their peers. To embody RAD is to champion the human spirit, and the irreplaceable value of love, friendship, and thoughtfulness. From a managerial perspective, if anything, RAD calls for a new approach to product development, and a willingness to see past deep-rooted behaviours, like search. Heretofore, social media was treated as a connective form of technology that brings people together, regardless of where they reside, or who they are. In many respects, that will always be the case. However, now that social media has evolved to a state of maturity and most Internet-connected denizens have adopted such tools into their communications regiment, it is time for practitioners to consider other possible applications. RAD postulates a social network that is marked by interpersonal closeness, and a shared intimacy among its members. As such, RAD is merely one way to construe this sentiment. Additional research could look into alternative methods in which Internet users are evolving with technology, and what other entrenched habits are subject to change in the coming years.

\subsubsection{Further Analysis of eWOM}

Much of the research presented earlier corroborated the omnipotence of WOM, even when evaluated against eWOM. Still and all, there was nothing particularly surprising about these findings, as the analyses were grounded in the conventional sense of eWOM. Namely, that eWOM occurs between one-to-many people in online environments, which is beset by anonymity. Thus, eWOM was reappraised, and adjusted to the sociocultural realities of the present day; now, a distinction has been drawn between the two interpretations. Aside from how and where consumers transmit recommendations with their peers, WOM and eWOM are one and the same. The in-person, physical exchange of 
information that is tantamount to our understanding of WOM will never cease to occur, and nor will its electronic-based equivalent.

Moving forward, eWOM should be examined on an even more granular level, to broaden our understanding of the phenomenon, and discern which avenues yield the strongest results. For instance, through text messages, email, a public post on social media, or a comment on OURS or consumer-oriented forums.

\subsubsection{The Semantic Web}

Following the mass adoption of Web 2.0 technologies, virtual travel communities like TripAdvisor and Atlas Obscura sprang forth, sowing the seeds of a new, people-driven hegemony (O'Reilly, 2005). Innovation, by nature, is a disruptive and merciless force; where Web 2.0 presaged the collapse of the travel agency, virtual travel communities-in their current manifestation-will likely suffer the same fate, but at the hands of Web 3.0. For all the debating, speculating, and theorizing, at present, what the Semantic Web entails is still a mystery. Some futurologists point to smart technology, where any object-regardless of its fundamental purpose-will be capable of sending and receiving information through the World Wide Web (Morrow, 2014). As alluded to earlier, others have envisioned a decentralized and competitive space that enjoys an even dispersion of Internet traffic (Hodgson, 2016). However, there is one facet that everyone seems to agree on: technologies will revolve around organic human behaviours, which comprises natural language and instinctual design. 


\section{Conclusion}

Consumers have long consulted their peers in pursuit of guidance, which is especially true in the domain of travel (Buhalis \& Law, 2008). In addition to its economic and logistical challenges, travel is such a powerful catalyst for WOM and eWOM because it institutes a commonality of interest, where cooperation is assured, and alliances are formed. Ultimately, when planning a trip or otherwise, information is sought for the sole purpose of reducing uncertainty and mitigating risk (Bigne et al., 2015). The tribulations of infobesity and, relatedly, the dilution effect, are everlasting forces of nature, which cannot be prevented. Aiding the consumer's undying quest for confidence in the decision-making process are the multitudes of online networks that foster eWOM. For travel, Internet users have relied on TripAdvisor, Atlas Obscura, Foursquare, and countless planning-oriented tools and booking systems. Howbeit, those participating in the aforementioned platforms do not know each other, personally, and thus are exchanging information in an anonymous setting. Whether these users are speaking truthfully or on behalf of a commercial entity is unknown: In the presence of anonymity, ascertaining trust is the consumer's responsibility (Cheung et al., 2009). All the same, there is an alternative to OURS and SAD tools, which was delineated earlier: relate-and-discovery (RAD). Even when compared alongside consumer opinions posted online, editorial content, or any form of paid advertising mediabe it traditional or online-WOM between friends and relatives has and will always produce the strongest results. In lieu of depending, entirely, on the opinions and viewpoints expressed by other, nameless consumers, RAD is another vehicle for discovering information that is tied to existing relationships, and thus not marred by skepticism. The efficacy and inborn credibility of a recommendation when it originates from a close friend 
or family member is, by a great amount, the most actionable, trustworthy, and cogent source of information (Nielsen, 2015).

Recommendations are the epitome of social capital: they allow people to connect over a mutually-held set of beliefs, interests, and values. When a consumer provides a recommendation, the information must be tailored to the unique needs and wants of whoever is on the receiving end, ensuring that the message is met warmly, and that both parties can gain from the transaction. While eWOM may have come to pass when the Internet was commercialized, it is simply a continuation of WOM, which, for all intents and purposes, is a perennial phenomenon. To date, consumers have not been exposed to a social tool that is expressly designed to facilitate eWOM. Subscribing to the tenets of RAD, Dispatch aims to replicate the success of OURS, social media platforms, and personal blogging services, but on a more intimate level; a space that offers comfortability, privacy, and communicative latitude to existing social groups who may have otherwise never exchanged such information. As Duffy (2015) found, 66 percent of travellers have not taken to online mediums to share their experiences. Seeing that travel is an experiential, intangible, and immensely popular activity, surely, any given traveller has a great deal of knowledge and insight to disseminate to their peers. In all likelihood, these individuals are sharing their experiences, but in-person, with those who care the most: friends and family.

Specialized Internet tools that embody RAD, such as Dispatch, are specifically designed to facilitate this exact breed of communication, where information is exchanged on the basis of reciprocity, and, ultimately, parlayed into action-whether or not that decision results in a purchase. Regardless of where a recommendation comes from-be it a publication's list-based article, a consumer's testimony on a review website, a high-ranking item on a democratized voting platform, or a local inhabitant of a particular region-the 
information is demonstrably more valuable because it stems from someone who is wellacquainted with the end user. As Aronson (1972) articulated in his seminal book on social psychology, "After all, a friend is someone you can trust and, hence, would be a far more credible source of information than someone you didn't like" (p. 209). 


\section{Bibliography}

Aronson, E. (1972). The Social Animal. New York: W.H. Freeman

Bigne, E., Andreu, L., Hernandez, B. \& Ruiz, C. (2015). The impact of social media and offline influences on consumer behaviour. An analysis of the low-cost airline industry. Current Issues in Tourism, 0(0), 1-19.

http://dx.doi.org/10.1080/13683500.2015.1126236

Blank, S. (2013). Why the Lean Startup Changes Everything. Harvard Business Review, May 2013. Retrieved from: https://hbr.org/2013/05/why-the-lean-start-up-changeseverything

Bonezzi, A., Dubois, D. \& De Angelis, M. (2016). Sharing with Friends Versus Strangers: How Interpersonal Closeness Influences Word-of-Mouth Valence. Journal of Marketing Research, 53(5), 712-727. http://dx.doi.org/10.1509/jmr.13.0312

Boswell, W. (2013). Why Users Uninstall Apps. Intel. Retrieved from URL: https://software.intel.com/en-us/blogs/2013/11/14/why-users-uninstall-apps

Buhalis, D. \& Law, R. (2008). Progress in information technology and tourism management: 20 years on and 10 years after the Internet-The state of eTourism research. Tourism Management. 29 (4), 609-623. doi:10.1016/j.tourman.2008.01.005

Center for Responsible Travel. (2016). The Case for Responsible Travel: Trends \& Statistics 2016. Washington, D.C., United States: Author. Retrieved from URL: http://www.responsibletravel.org/whatWeDo/The_Case_for_Responsible_Trave 1_2016_Final_UPDATED.pdf

Chari, S., Christodoulides, G., Presi, C., Wenhold, J. \& Casaletto, J.P. (2016). Consumer Trust in User-Generated Brand Recommendations on Facebook. Psychology E Marketing, 33(12), 1071-1081. doi: 10.1002/mar.20941 
Chen, A. (2008, November 3). Ad-based versus direct monetization: Which one is better for you? [Blog post]. Retrieved from URL: http://andrewchen.co/ad-based-versusdirect-monetization-which-one-is-better-for-you/

Chen, H., Hong, K. \& Yang, C.C. (2003). Visualization of large category map for Internet browsing. Decision Support Systems 35(1), 89-102. doi:10.1016/S0167-9236(02)00101$\mathrm{X}$

Cheung, M.Y., Luo, C., Sia, C.L. \& Chen, H. (2009). Credibility of Electronic Word-of-Mouth: Informational and Normative Determinants of On-line Consumer Recommendations. International Journal of Electronic Commerce, 13(4), 9-38. doi: 10.2753/JEC1086-4415130402

Constine, J. (2017, June 27). Facebook now has 2 billion monthly users... and responsibility. TechCrunch. Retrieved from URL: https://techcrunch.com/2017/06/27/facebook2-billion-users /

Creusen, M. E. H., \& Schoormans, J. P. L. (2005). The Different Roles of Product Appearance in Consumer Choice*. Journal of Product Innovation Management, 22: 63-81. doi:10.1111/j.0737-6782.2005.00103.x

Creusen, M.E.H., Veryzer, R.W, Schoormans \& J.P.L. (2010). Product value importance and consumer preference for visual complexity and symmetry. European Journal of Marketing, 44(9/10), 1437-1452. doi:10.1108/03090561011062916

Datta, A., Kajanan, S. \& Pervin, N. (2012). A Mobile App Search Engine. Mobile Networks and Applications, 18(1), 3-21. doi:10.1007/s11036-012-0374-2

Davis, Fred. (1989). Perceived Usefulness, Perceived Ease of Use, and User Acceptance of Information Technology. MIS Quarterly, 13 (3), 319-340. https://dx.doi.org/10.2307\%2F249008

Deis, M.H. \& Hensel, K. (2010). Using social media to increase advertising and improve marketing. The Entrepreneurial Executive, 15(9), 87-97. Retrieved from URL: http://www.alliedacademies.org/articles/eevol1512010.pdf\#page=95 
Delgado, H. (2017). The App Economy Forecast: \$6 Trillion in New Value. App Annie.

Retrieved from URL [App Annie]:

https://www.appannie.com/en/insights/market-data/app-economy-forecast-6trillion-market-making/

Duffy, A. (2015). Friends and fellow travelers: comparative influence of review sites and friends on hotel choice. Journal of Hospitality and Tourism Technology, 6(2), 127-144. doi:10.1108/JHTT-05-2014-0015

Edelman, D., Singer, M. (2015). The new consumer decision journey. McKinsey \& Company Quarterly, October 2015 Retrieved from URL: http://www.mckinsey.com/businessfunctions/marketing-and-sales/our-insights/the-new-consumer-decisionjourney

eMarketer. (2016). Worldwide Digital Travel Sales: The Complete eMarketer Forecast for 2016. Retrieved from URL: https://www.emarketer.com/Article/By-2020-DigitalTravel-Outlays-Will-Top-817-Billion-Globally/1014251

Ermagun, A., Fan, Y., Wolfson, J., Adomavicius, G. \& Das, K. (2017). Real-time trip purpose prediction using online location-based search and discovery services.

Transportation Research Part C, 77, 96-112. doi:10.1016/j.trc.2017.01.020

Google. (2016). How people discover, use, and stay engaged with apps. Retrieved from URL: https://www.thinkwithgoogle.com/_qs/documents/331/how-users-discoveruse-apps-google-research.pdf

Hamari, J., Hietaniemi, N., Kaptein, M., Parvinen, P. \& Pöyry, E. (2017). Personalized Product Recommendations: Evidence from the Field. Customer Analytics and Data-Led Omnichannel Commerce Minitrack. Retrieved from:

http://hdl.handle.net/10125/41626

Hernández-Méndez, J., Muñoz-Leiva, F. \& Sánchez-Fernández, J. (2015). The influence of eword-of-mouth on travel decision-making: consumer profiles. Current Issues in Tourism, 18(11), 1001-1021. doi:10.1080/13683500.2013.802764 
Hodgson, M. (2016, October, 9). A decentralized web would give power back to the people online. TechCrunch. Retrieved from URL: https://techcrunch.com/2016/10/09/adecentralized-web-would-give-power-back-to-the-people-online/

Hu, L., Lu, J., Mao, Z. \& Wang, M. (2015). Goodbye Maps, hello apps? Exploring the influential determinants of travel app adoption. Current Issues in Tourism, 18, 10571079. Retrieved from: http://dx.doi.org/10.1080/13683500.2015.1043248

ITB Berlin. (2016). ITB World Travel Trends Report 2016 / 2017. Berlin, Germany: Author. Retrieved from URL: http://www.itbberlin.de/media/itb/itb_dl_all/itb_presse_all/World_Travel_Trends_Report_2 016_2017.pdf

Johnson, G. D., \& Grier, S. A. (2013). Understanding the influence of cross-cultural consumer-to-consumer interaction on consumer service satisfaction. Journal of Business Research, 66, 306-313. http://dx.doi.org/10.1016/j.jbusres.2011.08.010

Kardes, F.R. (2002). Consumer Behavior and Managerial Decision Making (2nd ed.). Cincinnati, $\mathrm{OH}$ : University of Cincinnati

Kujala, S., Roto, V., Väänänen-Vainio-Mattila, K., Karapanos, E. \& Sinnelä, A. (2011). UX Curve: A method for evaluating long-term user experience. Interacting with Computers, 23(5), 473-483. doi:10.1016/j.intcom.2011.06.005

Luo, X. (2008). Quantifying the Long-Term Impact of Negative Word of Mouth on Cash Flows and Stock Prices. Marketing Science, 28(1), 148-165. Retrieved from: https://doi.org/10.1287/mksc.1080.0389

Mawhinney, J. (2017, January 3). 42 Visual Content Marketing Statistics You Should Know in 2017. HubSpot, Inc. Retrieved from URL: https://blog.hubspot.com/marketing/visual-content-marketingstrategy\#sm.0018f503cwi1cpv10vv1tlab4yft6 
McPherson, M., Smith-Lovin, L. \& Cook, J.M. (2001). Birds of a Feather: Homophily in Social Networks. Annual Review of Sociology, 27, 415-444.

https://doi.org/10.1146/annurev.soc.27.1.415

Monago, A. (2015, October 27). Brave New World: The Future of Search. [Blog post]. Retrieved from URL: https://medium.com/digital-marketing-and-strategy/bravenew-world-the-future-of-search-832dfaf38b69

Morrow, K. (2014, October 14). Web 2.0, Web 3.0, and the Internet of Things. UX Booth. Retrieved from URL: http://www.uxbooth.com/articles/web-2-0-web-3-0-andthe-internet-of-things /

Murphy, L., Mascardo, G. \& Benckendorff, P. (2007). Exploring word-of-mouth influences on travel decisions: friends and relatives vs. other travellers. International Journal of Consumer Studies, 31(5), 517-527. http://dx.doi.org/10.1111/j.1470-6431.2007.00608.x

Nielsen Holdings PLC. (2015). Global Trust in Advertising: Winning Strategies for an Evolving Media Landscape September 2015. Retrieved from URL:

https://www.nielsen.com/content/dam/nielsenglobal/apac/docs/reports/2015 /nielsen-global-trust-in-advertising-report-september-2015.pdf

Novet, J. \& Weber, H. (2015, August 18). Foursquare by the numbers: 60M registered users, $50 \mathrm{M}$ MAUs, and 75M tips to date. VentureBeat. Retrieved from URL:

http://venturebeat.com/2015/08/18/foursquare-by-the-numbers-60mregistered-users-50m-maus-and-75m-tips-to-date/

O'Reilly, T. (2005, October 30). What Is Web 2.0: Design Patterns and Business Models for the Next Generation of Software. [Blog post]. Retrieved from URL: http://www.oreilly.com/pub/a/web2/archive/what-is-web-20.html

Pabel, A. \& Prideaux, B. (2016). Social media use in pre-trip planning by tourists visiting a small regional leisure destination. Journal of Vacation Marketing, 22(4), 335-348. doi:10.1177/1356766715618998 
Prentice, R. (2006) Evocation and experiential seduction: updating choice-sets modelling. Tourism Management, 27, 1153-1170. doi:10.1016/j.tourman.2005.11.008

Puryear, R., Rogers, P. \& Root, J. (2013, June 11). Infobesity: The enemy of good decisions. Retrieved from URL [Bain \& Company]:

http://www.bain.com/publications/articles/infobesity-the-enemy-of-good$\underline{\text { decisions.aspx }}$

Reddit. (2015, February 20). Does anyone else barely post on their Facebook anymore? [Online forum]. Retrieved from: https://www.reddit.com/r/CasualConversation/comments/2wk8yh/does_anyon e_else_here_barely_post_on_their /

Reddit. (2015, September 15). People who "don't do Facebook," why not? [Online forum]. Retrieved from: https://www.reddit.com/r/AskReddit/comments/312xhl/people_who_dont_do _facebook_why_not/

Samson, A. (2006). Understanding the buzz that matters: negative vs positive word of mouth. International Journal of Market Research, 48(6), 647-657. Retrieved from: http://eprints.lse.ac.uk/21883/

TripAdvisor. (2015). TripBarometer Global Connected Traveler Report - June 2015 : Are you reaching the lucrative Connected Traveler? Retrieved from URL: https://www.tripadvisor.com/TripAdvisorInsights/n2642/are-you-reaching$\underline{\text { lucrative-connected-traveler }}$

Zomorodi, M. (Producer). (2017, July 26) Note to Self [Audio podcast]. Retrieved from: http://www.wnyc.org/story/escape-yahoo-verizon 